\title{
Challenges to the clinical placement and evaluation of adhesively-bonded, cervical composite restorations
}

Shisei Kubo ${ }^{a}$, Hiroaki Yokota ${ }^{\mathrm{b}}$, Haruka Yokota $^{\mathrm{b}}$ and Yoshihiko Hayashi ${ }^{\mathrm{c}}$

Address: ${ }^{a}$ Medical Education Development Center, Nagasaki University Hospital, Nagasaki, Japan

${ }^{\mathrm{b}}$ Clover Dental Clinic, Fukuoka, Japan

${ }^{c}$ Division of Cariology, Department of Developmental and Reconstructive Medicine, Nagasaki University, Nagasaki, Japan

Short title: Placement and evaluation of cervical composite restorations

\section{Corresponding author:}

Name: Shisei Kubo

Address: Medical Education Development Center, Nagasaki University Hospital, 1-7-1, Sakamoto, Nagasaki 852-8588, Japan

Phone: $\quad 81-95-819-7757$

Fax: $\quad 81-95-819-7757$

E-mail: $\quad$ kubo@nagasaki-u.ac.jp

\section{Keywords:}

resin composite, adhesive system, bond strength, bond durability, polymerization contraction stress, microleakage, clinical trial, non-carious cervical lesion 


\begin{abstract}
Objectives: The incidence of non-carious cervical lesions (NCCLs) has been increasing. The clinical performance of resin composites in NCCLS was previously unsatisfactory due to their non-retentive forms and margins lying on dentin. In order to address this problem, a lot of effort has been put into developing new dentin adhesives and restorative techniques. This article discusses these challenges and the criteria used for evaluating clinical performance as they relate to clinical studies, especially long-term clinical trials. Polymerization contraction, thermal changes and occlusal forces generate debonding stresses at adhesive interfaces.

Methods: In laboratory studies, we have investigated how these stresses can be relieved by various restorative techniques and how bond strength and durability can be enhanced. Lesion forms, restorative techniques, adhesives (adhesive strategies, bond strengths, bond durability, and the relationship between enamel and dentin bond strengths) were found to have a complex relationship with microleakage. With regard to some restorative techniques, only several short-term clinical studies were available.

Results: Although in laboratory tests marginal sealing improved with a low-viscosity resin liner, an enamel bevel or prior enamel etching with phosphoric acid, clinical studies failed to detect significant effects associated with these techniques. Long-term clinical trials demonstrated that adhesive bonds continuously degraded in various ways, regardless of the adhesion strategy used.
\end{abstract}

Significance: Early loss of restoration may no longer be the main clinical problem when reliable adhesives are properly used. Marginal discoloration increased over time and may become a more prominent reason for repair or replacement. Reliable and standardized criteria for the clinical evaluation of marginal discoloration should be 
established as soon as possible and they should be based on evidence and a policy of minimal intervention. 


\section{Introduction}

Non-carious cervical lesions (NCCLs), which may be caused by erosion, abrasion and/or occlusal stress ('abfraction'), are commonly observed in clinical practice [1]. Restorations for NCCLs are necessary to relieve hypersensitivity, to prevent further tooth structure loss, and to improve esthetics. Unfortunately however, the longevity of resin-based composite restorations for NCCLs was previously unsatisfactory compared to that of anterior approximal restorations [2]. The main reasons for failures were loss of the restoration, secondary caries and/or marginal discoloration [3-5]. This is probably because NCCLs have a non-retentive cavity shape and margins lying on dentin or cementum, which are unfavorable for bonding. In addition, the dentin in NCCLs tends to be sclerotic. Duke et al. [6] have suggested that the more sclerotic that dentin becomes, the more difficult it is to establish adhesion. When we started our laboratory studies, it was speculated that the prevalence of NCCLs would likely increase as a nation's population ages and as the survival times of teeth increase. For the benefit of public oral health, the clinical longevity of restorations for NCCLs requires an urgent improvement. In order to get more insight into this clinical problem, we first performed a series of laboratory studies on clinical placement techniques of cervical resin composite restorations by means of microleakage tests [7-26] and then we have been conducting 
clinical trials [27-32]. The aim of this article is to discuss the challenges we faced in the clinical placement and evaluation of cervical resin composite restorations as they relate to clinical studies, especially recently published, long-term clinical trials [33-39]. 


\section{Laboratory studies}

When considering the mechanisms of gap formation and debonding, two primary approaches appear to be necessary to improve the marginal sealing of cervical lesions. One is the relief of stresses generated by the inevitable polymerization contraction of a resin composite, thermal changes and occlusal forces, and the other is the enhancement of bonding strength and durability.

From 1990 to the year 2000, adhesive technology progressed rapidly and significantly. Most adhesive systems, meanwhile, were frequently replaced by a highly touted successor that lacked clinical validation. In these circumstances, it would be more practical to use laboratory screening tests of a restorative system than to perform clinical trials. If these screening tests were designed to closely simulate optimal clinical conditions, they would be much less expensive than clinical trials and not require several years to elicit meaningful outcomes [40]. In addition, laboratory testing can evaluate the effect of a single variable, if all the other variables are kept constant [40].

Generally the effectiveness of an adhesive system or a restorative technique is evaluated by bond strength tests or microleakage tests. In the past, many studies have failed to clearly demonstrate a close relationship between bond strength and microleakage $[41,42]$. This may be due to differences in fracture modes between the 
bond strength tests and the microleakage tests. In two-dimensional bond strength tests, most specimens show cohesive failure as bond strength increases. On the other hand, in three-dimensional microleakage tests, most gaps occur at the adhesive interfaces between cavity walls and restorative materials $[13,15]$. In this study, we mainly performed microleakage tests since they are more useful in demonstrating the polymerization contraction effect of resin composites as well as the effects of thermocycling and mechanical load cycling.

The basic design of our microleakage tests is briefly described below. Cavities were prepared at the cemento-enamel junction on the labial surfaces of bovine teeth. These cavities were treated with adhesive systems, following the instructions provided by each adhesive manufacturer. A hybrid resin composite was then filled in one increment into the cavities and cured for 60 seconds. After storage in tap water for assigned periods, the specimens were finished, polished, and then divided into a control group and fatigue testing groups. In the fatigue testing groups, the specimens were subjected to a thermocycle $\left(5-60^{\circ} \mathrm{C}\right.$, dwell time of $15 \mathrm{sec}, 5000$ cycles $)$ or to a flexural load cycle (approximately $0.5 \mathrm{~mm}$ labio-lingual displacement at the incisal edge, 10,000 cycles, 1 $\mathrm{Hz}$ ), as shown in Fig. 1. After a 24-hour immersion in $0.5 \%$ aqueous solution of basic fuchsin, the teeth were sectioned through the center of the restorations, and the extent of 
dye penetration, at the incisal enamel (0-3 scale) and at the apical cementum/dentin margins ( $0-4$ scale), was evaluated. It should be noted that the criteria for microleakage at the dentin margins changed twice during the 10 year study period. This was done to discriminate differences between experimental groups since dentin bond strength and durability increased significantly during this ten year period of time. The data was analyzed using the Kruskal-Wallis test or the Mann-Whitney U-test $(\mathrm{p}<0.05)$.

\subsection{Relief of stresses generated by polymerization contraction, thermal changes and} mechanical loading

It has been reported that the relief of polymerization contraction stress of resin composites is related to cavity forms [43], the flow of resin composites [44,45], the application of flexible intermediate substances [46] and placement techniques [47]. When polymerization contraction of a resin composite exceeds the bond strength to a cavity wall, a gap at the adhesive interface occurs. Even if a gap does not occur, residual stress remains at the adhesive interface after polymerization. Greater residual stress would deteriorate the bond more easily as thermal changes or occlusal forces come into play. In addition, a small defect at the adhesive interface may become a starting point for

a fatigue fracture. Although there has been no evidence that thermocycling or mechanical load cycling tests can accurately predict the real life durability of clinical 
resin composite restorations, these fatigue tests were carried out just to evaluate the bond durability of the adhesives we tested.

\subsubsection{The effect of NCCL forms}

Although various NCCL forms are observed [48], only the box form or V-shaped cavities were prepared in many microleakage vitro studies of cervical resin composite restorations. Generally, NCCLs in Japan have been restored using adhesive materials without a cavity preparation (except for the use of an enamel bevel), following the principle of minimally invasive restorative dentistry established by Fusayama [49]. Therefore, in our studies [7,9], we prepared three cavity designs which simulated typical NCCLs (viz. wedge-shape (W), V-shape (V) and U-shape (U)) at the cemento-enamel junction on the labial surfaces of bovine teeth (Fig. 2). These cavities were treated with Clearfil Liner Bond System, using a 4-step etch-and-rinse adhesive (Kuraray Medical, Tokyo, Japan). Although Protect Liner, a low-viscosity resin, was recommended by the manufacturer to be applied in a 4-step process, specimens without Protect Liner were also prepared to more easily display the effect of polymerization contraction stress.

The microleakage scores are given in Table 1. The incisal enamel margins showed no microleakage, regardless of the cavity design. The Liner Bond System adhesive exhibited significantly higher bond strength to enamel than to dentin [50]. The 
leakage pattern of this adhesive system may be attributed to its adhesive property. Only the W-cavities showed good marginal sealing in all experimental groups. Feilzer et al. [43] reported that the magnitude of polymerization contraction stress is greatly affected by the configuration of a cavity, and it increased as the C-value (the ratio of bonded surface to unbonded surface) increased. It is assumed that the C-value is related to the ratio of the cavity wall length to the free surface length in the bucco-lingual sectioned surface of a cavity. The values of these ratios for the $\mathrm{W}-, \mathrm{V}$ - and $\mathrm{U}$-shaped cavities were approximately $1.3,1.3$ and 1.9 , respectively. In addition, it was demonstrated that a thinner resin composite layer might have less influence on contraction stress than a thicker layer [51]. Therefore, significantly greater polymerization contraction stress may be generated at the cavity walls of a U-shaped cavity than at the cavity walls on $\mathrm{W}$ and V-shaped cavities.

It is speculated that if a gap occurs in any portion of a cavity, there may be a significant decrease of the induced stress at the other adhesive interface [52]. Therefore, the remaining bond could easily withstand contraction, thermal and mechanical stresses. Therefore, microleakage patterns may change and depend on cavity forms if an adhesive with high dentin bond strength is used. In order to verify this hypothesis, we investigated the microleakage patterns of $\mathrm{W}$ - and U-shaped cavities, which were prepared 
on the labial surfaces of either the cemento-enamel junction or on the roots of the teeth.

Because Clearfil Liner II displayed similar bond strength to both enamel and dentin, we used this adhesive for the investigation of microleakage patterns [12]. The microleakage scores are listed in Table 2. All of the specimens exhibited a good marginal seal when they were finished after 24 hours of storage in water. However, immediate finishing followed by thermal stress significantly deteriorated the marginal integrity. No significant differences in the microleakage patterns were observed between the cervical cavities and the root cavities, regardless of the cavity design. These results may be attributed to the adhesive property of the adhesive system used. On the other hand, the microleakage pattern observed in the $\mathrm{W}$-shaped cavities was quite different from that in the U-shaped cavities. The incisal portion of a W-shaped cavity has a thicker resin composite layer than the gingival portion, and greater stress development may result at the incisal margins [51]. For U-shaped cavities, similar contraction stresses are assumed to be generated at both the incisal and the gingival margins, since its longitudinal section has a symmetrical configuration. As a result, microleakage mainly occurred at the incisal margins in $\mathrm{W}$-shaped cavities, whereas it occurred at both the incisal and apical margins in U-shaped cavities. Our hypothesis turned out to be correct.

Earlier clinical studies suggested that clinical performance of resin composite 
restorations in NCCLs was affected by occlusal stress [53,54]. Although several in-vitro studies of microleakage under loading were attempted, the effects of load cycling on marginal seals were not clearly demonstrated $[55,56]$. This is possibly because axial loads were applied to the specimens in those studies. Flexural loads seem preferable for cervical restorations, since the etiology of NCCLs is likely related to eccentric occlusal forces [57]. A lateral displacement of approximately $0.5 \mathrm{~mm}$ or $1 \mathrm{~mm}$ is much greater than that encountered in clinical situations. However, this magnitude of displacement was applied in order to magnify the effect of loading. The W- and U-shaped cavities were restored at the cemento-enamel junction with 3 types of adhesives and a hybrid resin composite. This data is listed in Table 3. Flexural loading significantly impaired the marginal integrity of both cavity designs, even though the microleakage patterns were different. In the case of U-shaped cavities, only the marginal seal at the apical margins was impaired by loading, regardless of the adhesive system used. In spite of this, no bond deterioration was observed at the incisal margins. Generally, in a cantilever, the moment increases as the distance from the application point increases. Therefore, more stress may be generated at the apical margins than at the incisal margins, and this was clearly observed in the exclusive marginal seal deterioration at the apical margins. In the case of W-shaped cavities, the microleakage patterns depended on the adhesives used. 
For Single Bond (a 2-step etch-and-rinse system, 3M ESPE, St. Paul, MN, USA), no bond deterioration was observed. For Photo Bond (an early 2-step etch-and-rinse system without primer, Kuraray Medical), microleakage occurred only at the dentin margins. However, for Liner Bond II-V and Mac-Bond II (2-step self-etch systems), microleakage mainly occurred at the enamel margins. Finite element analysis indicated that more normal stress was induced on the incisal wall than on the apical wall [58]. The properties of individual adhesives may also affect these leakage patterns.

Long-term clinical trials demonstrated that the shape, size and location of NCCLs and the degree of sclerosis did not affect clinical performance [28,34,37-39]. In addition, our clinical trial revealed that the size and depth of NCCLs had no influence on marginal discoloration [32].

\subsubsection{The effect of placement techniques}

It has been thought that incremental placement techniques reduce contraction stress, and that they lead to an improvement of marginal sealing [47]. Many studies on the effect of incremental placement techniques on marginal sealing and adaptation have been performed [59-64]. However, these results are debatable/dubious because the application techniques [59,60,63], adhesive systems [59-62], resin composites [60] and cavity forms [64] had an influence on the effectiveness of the placement techniques. 
Moreover, mathematical analysis of the stresses generated by polymerization suggested that there are problems associated with incremental filling techniques, such as higher tensile stress concentrations at the restoration-enamel interface than those found with single-increment fillings [65].

Our previous studies [7,9] revealed that U-shaped cervical lesions created an intrinsic morphological deficiency on marginal sealing. Therefore, the effect of placement techniques was investigated using U-shaped cavities [10]. The materials and methods used in this study were the same as those in previous studies, with the exception of placement techniques. In the case of the bulk placement technique, the resin composite was cured for 60 seconds, whereas in the case of incremental placement techniques, each increment was cured for 30 seconds (Fig. 3). Microleakage scores are shown in Table 4. When the cavities were restored without Protect Liner, incremental techniques using oblique layers led to a significant improvement in the marginal seal. There was no significant difference between the bulk placement technique and the incremental placement technique with parallel layers. This result supports a similar finding reported by Hansen [63]. The incremental placement techniques that use oblique layers could possibly reduce not only the C-value but also the thickness of a resin composite. As a result, polymerization contraction stress might be decreased by using 
these placement techniques. Although placement techniques were found to have no significant effect on marginal sealing when the cavities were restored with Protect Liner, an incremental placement with oblique layers is recommended to restore large and/or deep NCCLs. Regarding the clinical study, no randomized controlled clinical trial (RCT) on the effect of placement techniques was retrieved using a PubMed search.

\subsubsection{The effect of a low-viscosity resin lining}

Kemp-Scholte \& Davidson [46] demonstrated that an intermediate unfilled resin layer between the adhesive resin and the resin composite relieved the polymerization contraction stress of the composite by 20 to $50 \%$. An intermediate layer of a low-viscosity resin composite or a filled adhesive resin may also act as an elastic buffer to relieve the stresses within composite restorations generated by polymerization contraction, thermal changes and occlusal forces [66]. However, Swift et al. [67] reported that the addition of low-viscosity resin composites to adhesive systems, which were not designed for use with such low-viscosity resin composites, did not reduce microleakage.

No consistent results were obtained in our studies with regard to the effect of using a low-viscosity resin liner $[7,10,12,23]$. This is probably because cavity designs with a low C-factor, placement techniques, high tooth-tissue bond strengths and thick 
filled adhesive layers conceal the effect of the application of the low-viscosity resin composite liner. However, overall findings suggest that the use of a low-viscosity resin composite liner possibly relieves the stresses on the adhesive interfaces generated by polymerization, thermal changes and occlusal forces, and may lead to an improvement in the durability of marginal sealings (Table 1,4,5).

An RCT [68] reported that the use of a flowable resin as a liner under a microhybrid resin composite did not improve the clinical performance of resin composite restorations in NCCLs within a 2-year period. In that clinical trial, the flowable resin composite was placed only on the bottom of the cavity. This placement is different from our study because we applied the low-viscosity resin composite to all of the cavity walls as well.

\subsubsection{The effect of flowable resin composites}

The application of a low-viscosity resin composite liner requires one additional step and, because of this, clinicians are less likely to accept this procedure. In the late 1990s, flowable composites were introduced to the market as a new type of resin composite. These restorative materials are created by retaining the same small particle sizes of traditional hybrid resin composites and reducing the filler content by 20 to 25 Wt\% [69]. The resulting composite has a lower viscosity and an elastic modulus which 
is $33-50 \%$ that of hybrid composites [69]. Despite a limited amount of clinical data, flowable resin composites have been becoming popular because they are easier to handle. Composites with a lower filler content and/or elastic modulus showed better marginal sealing in Class V restorations than composites with higher filler content [70]. Therefore, flowable composites would likely demonstrate good marginal sealing and provide a simplified clinical procedure.

The experimental design and methods used in the study [24] were the same as those used in a previous study [23], with the exception of the restorative materials used. When the restored teeth were not subjected to thermocycling or flexural load cycling, there were no significant differences observed in the microleakage patterns and scores between the flowable composites and the hybrid composite (Table 6). The volumetric polymerization contraction of resin composites is related to the filler content, and it decreases as the filler content increases [71]. On the other hand, the elastic modulus of the resin composite mainly depends on the filler content, and it increases as the filler content increases [72]. Accordingly, flowable composites shrink more and are less rigid than hybrid composites, and thus the interfacial stress build-up for flowable composites cannot be easily predicted [73]. The configuration of a cavity is a more important factor in flow related stress reduction than the type of resin composite used $[43,44]$. Microleakage scores of the 
control group indicate that the polymerization contraction stress may be similar to the bond strength of AQ Bond, regardless of the resin composite used. When the restored teeth were subjected to thermocycling or flexural load cycling, significant differences were observed between the flowable and hybrid composites. Thermocycling deteriorated the marginal integrity of the flowable resin composites, irrespective of the adhesive system used. On the contrary, flexural load cycling did not cause deterioration of the marginal integrity of the flowable composites, resulting in better marginal seals compared to that of the hybrid composite. It should be noted that the adhesive systems used also greatly affect the microleakage patterns that were observed.

In clinical situations, the handling properties of flowable resin composites seem to be very useful for placement procedures involving small or shallow non-carious cervical lesions. However, the overall findings of our study may raise concerns about the marginal sealing of relatively large cervical lesions if they are restored with flowable resin composites. Three RCTs $[30,74,75]$ reported no significant differences in clinical performance between flowable resin composites and microfilled or hybrid resin composites over a 3-year time frame. However, our ongoing RCT [32] revealed that the flowable resin composite had significantly more deterioration between 3 and 6 years than that of the hybrid resin composite. Recently, various types of flowable composites such 
as high-, medium-, low- and non-flow have been developed and they are touted as having improved mechanical properties. Further clinical study is required to assess these new products.

\subsubsection{The effect of an enamel bevel}

Enamel etched with $30-40 \%$ phosphoric acid shows sufficient bond strength to prevent gap formation. Our previous studies revealed that the marginal integrity at enamel margins treated with maleic acid or self-etch primer was degraded by thermocycle or flexural load cycling [14,20]. An enamel bevel significantly improved the marginal sealing at enamel margins, as shown in Table $7[17,22]$. The enamel bevel reduces the thickness of the resin composite and changes the cavosurface angle. This may lead to a reduction of stresses generated by polymerization contraction, thermal load cycling and flexural load cycling $[17,22,76]$.

With regard to clinical studies, only two RCTs were available. Both of them showed that the enamel bevel had no effect on clinical performance of resin composite restorations in NCCLs over a 3-year time frame [75,77].

\subsubsection{The effect of light curing modes}

Flow capacity may also depend on polymerization kinetics [45]. Several studies have revealed that greater shrinkage stress is generated at adhesive interfaces 
during the polymerization of light-cured resin composites than that of chemical-cured resin composites $[78,79]$. This is probably a result of the fact that light-cured resin composites polymerize at a faster rate than chemical-cured resin composites. Although polymerization rate reduction may be achieved by decreasing light intensity [79-82], low light intensity decreases the degree of conversion that is associated with the mechanical properties of the resin composites, and this may result in poor clinical performance of the restorations [83]. Most of the stress reduction is believed to occur during the first $10 \mathrm{~s}$ of light activation [78]. Therefore, 'soft-start' polymerization modes, such as the two-step mode and the ramping mode have been developed. These curing modes could significantly reduce shrinkage stress during polymerization $[84,85]$. However, 'soft-start' polymerization has not displayed any consistent effect on marginal integrity [86-88]. In addition, curing techniques involving very high light intensities, such as plasma arc curing (PAC) and xenon lamp curing, have been introduced to the market $[89,90]$. The irradiation time recommended by the manufacturers is 3 to $5 \mathrm{~s}$ for resin composite restorations. Although it is reasonable to expect a negative effect of such a rapid polymerization process on marginal integrity, this has yet to be confirmed [89]. In our study [25], no significant differences in the microleakage scores were found among the light-curing modes used (standard, two-step, ramping and PAC modes), as 
shown in Table 8. In addition, relatively good marginal integrity was obtained, regardless of the light-curing mode used. These findings suggest that light-curing modes may have no effect on microleakage in cervical cavities with a small C-factor and a shallow cavity depth when they are restored with a reliable adhesive. Unfortunately, no RCT investigations are available concerning the effect of light-curing modes.

\subsubsection{The effect of finishing and polishing}

Immediate finishing and polishing followed by thermocycling significantly deteriorated marginal integrity (Table 1). It may be possible, over time, to relieve any residual stress resulting from polymerization contraction by relaxation and hygroscopic expansion. Possibly, residual stress still exists shortly after light activation. In this circumstance, thermocycling may have more of an effect on marginal integrity. Furthermore, a post-cure interval of 24 hours may enhance mechanical and adhesive properties of resin composites [91]. These findings suggest that it is better to postpone finishing and polishing until the patient's next visit, especially for a NCCL with a high C-value. No clinical study is available concerning the effect of finishing/polishing time. 


\subsection{Enhancement of bond strength and durability}

If an adhesive had a sufficiently strong bond and it was durable enough to overcome polymerization contraction stress and fatigue stresses caused by thermal changes and occlusal forces, good marginal integrity would be maintained over a long period of time. The tensile bond strengths of adhesives to bovine enamel and dentin that were determined by our laboratory are given in Table 9 .

\subsubsection{Enhancement of bond strength to dentin}

Until the middle of the 1990s, it was estimated that a 17-24 MPa bond strength was required to prevent a gap formation between restorative materials and dentin cavity walls [92,93]. Bond strengths of adhesives to enamel had already reached this range with the use of phosphoric acid etching, whereas the bonding of earlier adhesive systems to dentin exhibited bond strengths less than $10 \mathrm{MPa}$. Therefore, the sustained effort of many researchers has led to the development of adhesive systems which show high bond strengths to dentin. The evolution of so-called fourth generation adhesive systems has resulted in the production of 2-step self-etch adhesives and 3-step etch-and-rinse adhesives. Dentin bond strengths are remarkably enhanced by these adhesives and are similar to enamel bond strength [11,13]. Contrary to our expectation, we were unable to demonstrate an improvement of dentin marginal sealing as a result of dentin bond 
strength enhancement in the studies, as shown in Tables $1-3$ and $10[11,14,18]$. In the case of self-etch adhesives, marginal sealing at enamel margins was degraded by thermocycling and flexural load cycling, regardless of the cavity form. Polymerization contraction stress is significantly reduced by gap formation, as described in the section of the effect of NCCLs forms [52]. In other words, if polymerization contraction stress exceeds bond strength, this stress increases with bond strength. Therefore, not only the absolute values of bond strengths but also the relative relationship between enamel and dentin bond strengths may significantly affect the microleakage patterns of cervical resin composite restorations. In addition, it is likely that bond durability and stress distribution affect the microleakage caused by fatigue testing.

After dentin bond strengths reached a sufficient level to prevent early clinical failures, manufacturers focused on the simplification of clinical procedures. As a result, 2-step etch-and-rinse adhesives and 1-step self-etch, so-called all-in-one, adhesives were introduced to the market in the late 1990s. A 2-step etch-and-rinse adhesive resulted in marginal sealing that was comparable to 2-step self-etch adhesives. In our clinical trial $[27,28]$, there was no significant difference between Liner Bond II (2-step self-etch) and Single Bond (2-step etch-and-rinse) when it came to 8-year survival rates. As predicted by the laboratory test [18], marginal discoloration occurred at both enamel and dentin 
margins for Liner Bond II, whereas discoloration occurred mainly at the dentin margins for Single Bond. However, it should be noted that marginal discoloration was probably caused by the accumulation of stains at the marginal step or crevice rather than as a result of microleakage. On the other hand, earlier 1-step self-etch adhesives showed significantly poorer marginal sealing, as shown in Table 11 [21,23]. A systematic review of clinical trials of resin composite restorations in NCCLs revealed the inefficient clinical performance of earlier 1-step self-etch adhesives [94]. In order to address the problems of these adhesives, several newer 1-bottle, 1-step self-etch adhesives (with a relatively thin adhesive layer) were developed in the middle of 2000s. The newer1-step self-etch adhesives improved marginal sealing and some products showed equivalent marginal sealing to that of 2-step self-etch adhesives, as shown in Table 11 [26]. Our clinical trials [27,31], which were performed using almost the same protocol, indicated that although there was no difference in 5-year survival rates between adhesives, the incidence and extent of marginal discoloration associated with the 1-step self-etch adhesives were greater than that of other 2-step adhesives. In addition, marginal discoloration of 1-step self-etch adhesives mainly occurred at enamel margins. These findings are supported by another medium-term clinical trial [95].

When NCCLs were restored in our clinic, a superficial layer of exposed dentin 
surface is removed using a round steel bur at slow speed. Although saliva contamination prior to priming did not significantly affect dentin bond strengths of the 2-step self-etch adhesive, SEM observations of primed dentin surfaces raised concerns about the durability of bonding to saliva contaminated dentin [96]. Recently, Van Dijken [38] reported that restorations placed in lesions slightly roughened before primer application showed lower loss rates than non-roughened ones.

\subsubsection{Enhancement of bond strength to enamel}

Enamel etched with $30-40 \%$ phosphoric acid shows sufficient bond strength to prevent microleakage. In most earlier adhesive systems, enamel and dentin were supposed to be treated separately since etching dentin with phosphoric acid might cause hyper sensitivity or pulpal inflammation [49]. However, in the case of fourth generation adhesive systems and 1-step self-etch adhesives, enamel and dentin are simultaneously treated with a milder acid, such as low concentration phosphoric acid, maleic acid, self-etch primers or self-etch adhesives. Our laboratory studies [11,12,14,18-21,26] indicated that marginal seals at enamel margins treated with these adhesives were degraded by thermocycling or flexural load cycling. A possible explanation for this leakage pattern is that bond strength and durability to enamel may be decreased by maleic acid treatment or the self-etch systems. 


\subsubsection{The effect of an enamel bevel}

Marginal sealing at incisal enamel margins was significantly improved by the bevel preparation, as shown in Table 7. This possibly because the enamel bevel decreases tensile stress at the adhesive interface generated by polymerization, thermal changes and flexural loading, as described above. In addition, the bevel increases bonded surface area, and might be able to enhance bond strength. Munechika et al. [97] reported that bond strengths to transverse sections were significantly higher than those to longitudinal sections of enamel prisms. The bevel produces an oblique section of enamel rods, and thus may result in enhancement of bond strength. However, SEM observations have revealed that the bevel preparation alone was not sufficient to prevent a gap formation at the enamel wall, even after 24-hour of storage in water [15]. Only a few clinical trials are available concerning the effect of enamel bevel on the clinical performance of resin composites in NCCLs [75,77]. Although self-etch systems were not used in these studies, they indicated that the enamel bevel had no effect on survival rates after 3 years of clinical service.

\subsubsection{The effect of the application time of dentin/enamel conditioners}

With respect to maleic and oxalic acid, the use of etching times that are longer than recommended by the manufactures showed significantly higher bond strengths [98]. 
For a self-etch primer, a longer application time also improved the sealing ability at both enamel and dentin margins [99].

\subsubsection{The effect of prior enamel etching with phosphoric acid}

Marginal sealing of 2-step self-etch adhesives and a 3-step etch-and-rinse adhesive with maleic acid was significantly improved by prior enamel etching with phosphoric acid, as shown in Table 12 [16]. An explanation for this is an increase of bond strength to enamel. The degree of surface roughness produced by phosphoric acid is greater than that obtained with the self-etch primer or maleic acid because of its lower pH. This increased surface roughness may possibly provide higher bond strength because the bonding of a resin composite to enamel is mainly based on micromechanical retention [100]. From a clinical point of view, it is almost impossible to prevent an accidental contact of etched enamel with maleic acid or a self-etch primer. Fortunately, the application of the self-etch primer or maleic acid to etched enamel showed no adverse effect on enamel bond strengths or marginal sealing in our study [16]. However, addition etching with phosphoric acid should be limited to enamel since prior dentin etching with phosphoric acid significantly decreased the dentin bond strength [101]. It should be noted that prior enamel etching with phosphoric acid alone could not prevent microleakage when the restorations were subjected to thermocycling. Only prior enamel 
etching with phosphoric acid in conjunction with an enamel bevel could eliminate microleakage (Table 7). Peumans et al. [39] have reported that enamel etching with phosphoric acid prior to the SE Bond primer had only a few minor effects on marginal integrity and marginal discoloration at enamel after 8 years of clinical service. 


\section{Clinical studies}

Even if laboratory tests yield favorable results, they do not always result in good clinical performance $[41,102]$. Only a well-controlled clinical trial can provide the ultimate proof of clinical effectiveness. Although many clinical trials have been done, most clinical trials have assessed NCCLs over a time frame of less than 3 years. Therefore, we have been performing clinical trials of resin composite restorations in NCCLs over as long a period of time as possible [28,31,32]. Recently, several long-term (7 years or more) clinical trials of NCCLs have been published [33-39]. All of them demonstrated that adhesive bonds continuously degraded with wide variation and that this bond degradation was independent of the adhesion strategy used.

\subsection{Clinical problems associated with resin composite restorations in NCCLs}

Loss of restoration was the main clinical problem associated with resin composite restorations placed in NCCLs. The magnitude of dentin bond strength that is required to prevent a retention failure is still unclear. However, in our clinical trials, all adhesives used demonstrated excellent retention rates after 5 years, irrespective of the adhesion strategy used. For Liner Bond II and Single Bond, we observed a 100\% retention rate, and we observed a 97\% retention rate for S3 Bond and G-Bond. This result is supported by other long-term clinical trials [34,39]. Early loss of restoration 
may no longer be the main clinical problem when reliable adhesives are properly used.

Marginal discoloration is thought to be one of the first clinical signs that a resin composite restoration is prone to failure [103] and may become a more prominent reason for repair or replacement, especially in general practice, as reported by Browning and Dennison [3]. The incidence of marginal discoloration increased over time, ranging from 28 to $55 \%$ at 8 year recalls [28,34,36,39]. In our clinical studies, we used a similar protocol $[27,31]$ and discovered that, after 5 years of clinical service, one-step self-etch adhesives resulted in more marginal discoloration (40-50\%) than 2-step self-etch (19\%) and 2-step etch-and-rinse (17\%) adhesives.

The relationship between marginal discoloration and marginal adaptation has been indicated in many studies $[27,39,104]$. Indeed, marginal stains were always detected in combination with small marginal defects. However, not all the marginal defects resulted in marginal discoloration [27]. In addition, marginal adaptation seems to be a less common reason to replace cervical resin composite restorations than marginal discoloration [3]. With respect to other categories, such as secondary caries, color match, surface roughness and postoperative sensitivity, clinical problems rarely occurred even in long-term clinical trials [34,36-39]

\subsection{Clinical evaluation}


The original United States Public Health Service (USPHS) criteria were developed more than 40 years ago and have since become less sensitive for identifying differences between current materials [105]. In order to detect early deterioration, it would be helpful to have a more discriminative scale. Therefore, modified USPHS criteria have been widely used in clinical studies. The USPHS criteria use a grading system based on subjective observations of restorations. It is easy to obtain agreement on retention failure and bulk fracture from evaluator group of evaluators, whereas it is relatively difficult to obtain agreement on secondary caries, marginal discoloration and marginal adaptation. In addition, the transition zone between respective scales makes judgments difficult due to the lack of a clear definition.

Almost all of the marginal stains found in long-term clinical trials were clinically acceptable $[28,34,38,39]$. SEM observation suggested that marginal discoloration in our studies was caused by the accumulation of stains at marginal steps rather than by microleakage [27]. In addition, most marginal discoloration appeared to be removed by margin repolishing. Long-term observations revealed that the extent or progress of marginal discoloration displayed various patterns within the range of clinically acceptable score $[27,28,31,32]$. Therefore, for marginal discoloration, the Bravo score was subdivided further, as shown in Fig. 4, in order to aid in the detection of early 
differences between the restorative materials in our studies [29-32]. For marginal adaptation, the criterion was modified to be generous since marginal adaptation is evaluated more subjectively and it is a less common reason for replacements [28-32].

Meta-analysis provides a highly reliable measure of restoration longevity. However, meta-analysis of the clinical data of resin composite restorations seems to be difficult because of the ambiguity of USPHS criteria and the process of conducting and reporting clinical trials $[105,106]$. Chadwick et al. [107] comprehensively discussed the problems associated with outcome measures of restoration failures. There has been a need for the development of reliable and more objective criteria for clinical performance of restorations based on evidence and minimal intervention policy. In these circumstances, FDI criteria were published in 2007 and they should be applied as standard criteria when restorative materials and/or operative techniques are to be clinically investigated [105]. These criteria were updated in 2010, modifications and/or alternatives are possible if good documentation can be presented [108]. In addition, a web-based training and calibration tool called "e-calib", including several hundred clinical examples, was made available in July 2008. It will help to spread the information about the FDI criteria and to facilitate both training and calibration at the clinical level. Unfortunately, only examples of posterior resin composite restorations are 
available at present. In addition, they appear to need constant improvement.

Replacement criteria may have a great effect on the longevity of resin composite restorations $[3,105,106]$. Our questionnaire studies on decision-making $[109,110]$ revealed a wide variation in the treatments commonly used for marginal discoloration (Fig. 5 and Table 13). They also suggested that education, clinical experience and lifelong learning may have some influence on clinically-based decision making. Long-term monitoring of defective restorations has indicated that their progress is usually arrested within several years (Fig. 6). Therefore, monitoring of marginal discoloration is recommended to aid in proper decision-making. An open-access guideline like "e-calib" should be prepared for educators, dental students, general practitioners and patients. 


\section{References}

1. Levitch LC, Bader JD, Shugars DA, Heymann HO. Non-carious cervical lesions. J Dent 1994; 22 : 195-207.

2. Smales RJ, Gerke DC. Clinical evaluation of light-cured anterior resin composites over periods of up to 4 years. Am J Dent 1992; 5: 208-11.

3. Browning WD, Dennison. A survey of failure modes in composite resin restorations. Oper Dent 1996; 21: 160-6.

4. Peumans M, Kanumilli P, De Munck J, Van Landuyt K, Lambrechts P, Van Meerbeek B. Clinical effectiveness of contemporary adhesives: A systematic review of current clinical trials. Dent Mater 2005; 21: 864-81.

5. Kubo S, Yokota H, Hayashi H. Reasons for retreatment of resin composite restorations. the $126^{\text {th }}$ JSCD Meeting 2007; Program and abstracts: 20, Abstr. B-19.

6. Duke ES, Robbins JW, Snyder DS. Clinical evaluation of a dentinal adhesive system: three-year results. Quintessence Int 1991; 22: 889-95.

7. Kubo S, Watanabe T, Ohsawa M, Matsumoto H. Study on microleakage of cervical composite resin restorations. Part 1. Effect of erosive lesion forms and low-viscosity resin on marginal leakage. Jpn J Conserv Dent 1993; 36; 1115-22.

8. Kubo S, Watanabe T, Ohsawa M, Matsumoto H. Study on microleakage of cervical composite 
resin restorations. Part 2. The effect of the discrepancy of bond strength between enamel and dentin on microleakage and cavity adaptation. Jpn J Conserv Dent 11994; 37: 526-38.

9. Watanabe T, Kubo S, Ohsawa M, Matsumoto H. Study on microleakage of cervical composite resin restorations. Part 3. The influence of finishing time and thermal stress on marginal leakage. Jpn J Conserv Dent 199; 437: 1202-8.

10. Kubo S, Watanabe T, Ohsawa M, Matsumoto H. Study on microleakage of cervical composite resin restorations. Part 4. Effect of placement techniques on marginal leakage. Jpn J Conserv Dent 1994; 37: 1209-15.

11. Kubo S, Yokota H, Watanabe T, Ohsawa M, Matsumoto H. Adhesive properties of Liner Bond II (KB-110) system. Part 1. Relationship between marginal seal and tensile bond strength. Jpn J Conserv Dent 1994; 37: 1216-23.

12. Kubo S, Yokota H, Watanabe T, Ohsawa M, Matsumoto H. Adhesive properties of Liner Bond II system. Part 2. Effect of cavity forms and a low-viscosity resin on marginal sealing. Jpn J Conserv Dent 1994; 37: 1678-85.

13. Yokota H, Watanabe T, Kubo S, Ohsawa M. Adhesive properties of the fourth generation bonding system -Tensile bond strength and characterization of fractured surface-. Jpn J Conserv Dent 1996; 39: 1029-36.

14. Watanabe T, Kubo S, Yokota H, Ohsawa M. Study on microleakage of cervical composite resin 
restorations. Part 5. An evaluation of fourth generation bonding system. Jpn J Conserv Dent 1996;

39: $1504-10$.

15. Kubo S, Yokota H, Konishi Y, Watanabe T. Cavity adaptation fourth generation adhesive systems - in cervical cavities-. Jpn J Conserv Dent 1996; 39: 1511-22.

16. Sata Y, Kubo S, Yokota H, Watanabe T, Hayashi Y. Effect of enamel etching with phosphoric acid on marginal sealing of cervical resin composite restorations. Jpn J Conserv Dent 1999; 42: 909-18.

17. Yokota H, Sata Y, Kubo S, Hayashi Y. Effect of enamel bevel on microleakage of cervical resin composite restorations. Jpn J Conserv Dent 1999; 42: 982-8.

18. Kubo S, Yokota H, Sata Y, Hayashi Y. Microleakage of cervical resin composite restorations. In: Momoi Y, editor. Modern Trends in Adhesive Dentistry. Proceedings of the Adhesive Dentistry Forum 1999 in Tsurumi, Yokohama, Japan, Osaka: Kuraray Co., Ltd.; 2000. p. 153-64.

19. Kubo S, Yokota H, Sata Y, Hayashi Y. Microleakage of self-etching primer systems after thermal and flexural load cycling. Am J Dent 2001; 14: 163-9.

20. Kubo S, Yokota H, Sata Y, Hayashi Y. The effect of flexural load cycling on the microleakage of cervical resin composite restorations. Oper Dent 2001; 26: 451-9.

21. Kubo S, Yokota H, Yokota H, Hayashi Y. Bond strengths and microleakage of new 
adhesive systems. In: Yoshiyama M, editor. Modern Trends in Adhesive Dentistry. Proceedings of the Adhesive Dentistry Forum 2001 in Okayama, Japan, Tokyo: Kuraray Medical Inc.; 2002. p. 15-30.

22. Kubo S, Yokota H, Yokota H, Hayashi Y. The effect of enamel bevel on the microleakage of cervical resin composites. Fourth Int Congress on Dental Materials 2002; Transactions: 252, Abstr. No. 117.

23. Kubo S, Yokota H, Yokota H, Hayashi Y. Effect of low-viscosity resin-based composite on the microleakage of cervical restorations, Am J Dent 2003; 16: 244-8.

24. Kubo S, Yokota H, Yokota H, Hayashi Y. Microleakage of cervical cavities restored with flowable composites. Am J Dent 2004; 17: 33-7.

25. Kubo S, Yokota H, Yokota H, Hayashi Y. The effect of light-curing modes on the microleakage of cervical resin composite restorations, J Dent 2004; 32: 247-54.

26. Kubo S, Yokota H, Yokota H, Hayashi Y. Microleakage of cervical resin composites restored with one-step self-etch systems. J Dent Res 2005; 84: Abstr. No. 3105.

27. Kubo S, Yokota H, Kawasaki K. Hayashi Y. Five-year clinical evaluation of two adhesive systems in non-carious cervical lesions. J Dent 2006; 34, 97-105.

28. Kubo S, Yokota H, Kawasaki K. Hayashi Y. Eight-year clinical evaluation of two adhesives in non-carious cervical lesions. J Dent Res 2008; 87: Abstr. No. 1786. 
29. Kubo S, Yokota H, Yokota H, Hayashi Y. Two-year clinical evaluation of one-step self-etch systems in non-carious cervical lesions. J Dent 2009; 37: 149-55.

30. Kubo S, Yokota H, Yokota H, Hayashi Y. Three-year clinical evaluation of a flowable and a hybrid resin composite in non-carious cervical lesions. J Dent 2010; 38: 191-200.

31. Kubo S, Kawasaki A, Kawakubo A, Hayashi Y. Five-year clinical evaluation of two all-in-one systems. J Dent Res 2011; 90: Abstr. No. 1144.

32. Kubo S, Yokota H, Yokota H, Hayashi Y. Six-year clinical evaluation of resin composites in non-carious cervical lesions. J Dent Res 2012; 91: Abstr. No. 27.

33. Van Dijken JWV, Sunnegårdh-Grönberg K, Lindberg A. Clinical long-term retention of etch-and-rinse and self-etch adhesive systems in non-carious cervical lesions. A 13 tears evaluation. Dent Mater 2007; 23: 1101-7.

34. Peumans M, De Munck J, Van Landuyt KL, Kanumilli P, Yoshida Y, Inoue S, Lambrechts P, Van Meerbeek B. Restoring cervical lesions with flexible composites. Dent Mater 2007; 23: 749-54.

35. Van Dijken JWV, Pallesen U. long-term dentin retention of etch-and-rinse and self-etch adhesives and a resin-modifies glass ionomer cement in non-carious cervical lesions. Dent Mater 2008; 24: 915-22.

36. Ritter AV, Swift EJ Jr, Heymann HO, Sturdevant JR, Wilder AD Jr. An eight-year clinical evaluation of filled and unfilled one-bottle dental adhesives. J Am Dent Assoc 2009; 140: 28-37. 
37. Wilder AD Jr, Swift EJ Jr, Heymann HO, Ritter AV, Sturdevant JR, Bayne SC. A 12-year clinical evaluation of a three-step dentin adhesive in noncarious cervical lesions. J Am Dent Assoc 2009; 140: 526-35.

38. Van Dijken JWV. A prospective 8-year evaluation of a mild two-step self-etching adhesives and a heavily filled two-step etch-and-rinse system in non-carious cervical lesions. Dent Mater 2010; 26: 940-6.

39. Peumans M, De Munck J, Van Landuyt KL, Poitevin A, Lambrechts P, Van Meerbeek B. Eight-year clinical evaluation of a 2-step self-etch adhesive with and without selective enamel etching. Dent Mater 2010; 26: 1176-84.

40. Van Meerbeek B, De Munck J, Yoshida Y, Inoue S, Vargas M, Vijay P, van Landuyt K, Lambrechts P, Vanherle G. Adhesion to enamel and dentin: current status and future challenges. Oper Dent 2003; 28: 215-35.

41. Finger WJ. Dentin bonding agents. Relevance of in vitro investigations. Am J Dent 1988; 1: $184-8$

42. Fortin D, Swift EJ, Denehy GE, Reinhardt JW. Bond strength and microleakage of current adhesives. Dent Mater 1994; 10: 253-8.

43. Feilzer AJ, de Gee AJ, Davidson CL. Setting stress in composite resin in relation to configuration of the restoration. J Dent Res 1987; 66: 1631-9. 
44. Davidson CL, de Gee AJ. Relaxation of polymerization contraction stresses by flow in dental composite. J Dent Res 1984; 63: 146-8.

45. Feilzer AJ, de Gee AJ, Davidson CL. Quantitative determination of stress reduction by flow in composite restorations. Dent Mater 1990: 6, 167-11.

46. Kemp-Scholte CM, Davidson CL. Complete marginal seal of class V resin composite restorations effected by increased flexibility. J Dent Res 1990; 69: 1240-3.

47. Rupp NW. Clinical placement and performance of composite resin restorations. J Dent Res 1979; 58: 155-7.

48. Nakajima F. A Morphological study on the restoration of tooth wedged-shaped defects with composite resin. Jpn J Conserv Dent 1984; 27: 295-313.

49. Fusayama T. A simple pain-free adhesive restorative system by minimal reduction and total etching. Ishiyaku Euro America Inc, St. Louis 1993.

50. Hosoda H, Hirasawa K, Fujitani M. New tooth surface conditioning treatment for adhesive composite restorations. Jpn J Conserv Dent 1989; 32: 421-33.

51. Hosoda H, Fujitani M, Negishi T, Hirasawa K. Effect of a series of new cavity surface treatment on bond strength and wall adaptation of adhesive composite resins. Jpn J Conserv Dent 1989; 32: $656-65$.

52. Nemoto K, Komatsu K, Horie K, Tomotsune K, Bowen RL. Shrinking stress of composite resin 
during hardening. Part I. Design of the apparatus and shrinking stress of chemically cured and light cured resin. J J Dent Mater 1992; 11: 697-702.

53. Heymann HO, Sturdevant JR, Bayne S, Wilder AD Jr, Sluder TB, Brunson WD. Examining tooth flexure effects on cervical restorations: A two-year clinical study. J Am Dent Assoc 1991; 122: 41-7.

54. Van Meerbeek B, Braem M, Lambrechts P, Vanherle G. Evaluation of two dentin adhesives in cervical lesions. J Prosthet Dent 1993; 70: 308-14.

55. Rigsby DF, Retief DH, Bidez MW, Russell CM. Effect of axial load and temperature cycling on microleakage of resin restorations. Am J Dent 1992; 5: 155-9.

56. Davidson CL, Abdalla AI. Effect of occlusal load cycling on the marginal integrity of adhesive Class V restorations. Am J Dent 1994; 7: 111-4.

57. Lee WC, Eakle WS. Possible role of tensile stress in the etiology of cervical erosive lesions of teeth. J Prosthet Dent 1984; 52: 374-80.

58. Yokota H, Kawaguchi M Yokota H, Ohsawa M, Kubo S, Hayashi Y. Finite element analysis of cervical resin composite restoration. Jpn J Conserv Dent 2006; 49: 574-81.

59. Crim GA. Microleakage of three resin placement techniques. Am J Dent 1991; 4: 69-72.

60. Torstenson B, Oden A. Effects of bonding agent types and incremental techniques on minimizing contraction gaps around resin composites. Dent Mater 1989; 5: 218-23. 
61. Zidan O, Gomez-Marin O, Tsuchiya T. A comparative study of the effects of dentinal bonding agents and application techniques on marginal gaps in class V cavities. J Dent Res 1987; 66: $716-21$.

62. Linden J, Swift EJ. Microleakage of two new dentin adhesives. Am J Dent 1994; 7: 31-34.

63. Hansen EK. Effect of cavity depth and application technique on marginal adaptation of resins in dentin cavity. J Dent Res 1986; 65: 1319-21.

64. Hansen EK, Asmussen E. Marginal adaptation of resin in relation to application technique and use of a calcium hydroxide liner. Scand J Dent Res 1990; 98 558-63.

65. Versluis A, Douglas WH, Cross M, Sakaguchi RL. Does an incremental technique reduce polymerization shrinkage stresses?. J Dent Res 1996; 75: 871-8.

66. Van Meerbeek B, Willems G, Celis JP, Roos JR, Braem M, Lambrechts P, Vanherle G. Assessment by nano-indentation of the hardness and elasticity of the resin-dentin bonding area. $\mathrm{J}$ Dent Res 1993; 72: 1434-42.

67. Swift EJ, Triolo PT, Barkmeier WW, Bird JL, Bounds SJ. Effect of low-viscosity resins on the performance of dental adhesives. Am J Dent 1996; 9 100-4.

68. Reis A, Loguercio AD. A 24-month follow-up of flowable resin composite as an intermediate layer in non-carious cervical lesions. Oper Dent 2006; 31: 523-9.

69. Bayne SC, Thompson JY, Swift EJ, Stamatiades P, Wilkerson M. A characterization of 
first-generation flowable composite. J Am Dent Assoc 1998; 129: 567-77.

70. Kemp-Scholte CM, Davidson CL. Marginal sealing of curing contraction gaps in Class V composite resin restorations. J Dent Res 1988; 67: 841-5.

71. Tsuruda H. Effect of filler shape, particle size and filler content in composite resins on shrinkage stress during setting. Jap I Dent Mater 1994; 13: 575-85.

72. Willems G, Lambrechts P, Braem M, Celis JP, Vanherle G. A classification of dental composites according to their morphological and mechanical characteristics. Dent Mater 1992; 8: 310-9.

73. Labella R, Lambrechts P, Van Meerbeek B, Vanherle G. Polymerization shrinkage and elasticity of flowable composites and filled adhesives. Dent Mater1999; 15: 128-37.

74. Tyas MJ, Burrow MF. Three-year clinical evaluation of One-Step in non-carious cervical lesions. Am J Dent 2002; 15: 309-11.

75. Baratieri LN, Canabarro S, Lopes GC, Ritter AV. Effect of resin viscosity and enamel beveling on the clinical performance of Class V composite restorations: Three-year results. Oper Dent 2003; 28: 482-487.

76. Yokota H, Kawaguchi M Yokota H, Ohsawa M, Kubo S, Hayashi Y. Finite element analysis of cervical resin composite restoration -The effect of enamel bevel on stresses generated by thermal change and occlusal force-. Jpn J Conserv Dent 2007; 50: 545-52

77. Van Meerbeek B, Peumans M, Gladys S, Braem M, Lambrechts P, Vanherle G. Three-year 
clinical effectiveness of four total-tech dental adhesive systems in cervical lesions. Quintessence Int 1996; 27: 775-784.

78. Feilzer AJ, de Gee AJ, Davidson CL. Setting stress in composites for two different setting modes. Dent Mater 1993; 9: 2-5.

79. Bouschlicher MR, Vargas MA and Boyer DB. Effect of composite type, light intensity, configuration factor and laser polymerization on polymerization contraction forces. Am J Dent 1997; 10: 88-96.

80. Feilzer AJ, Dooren LH, de Gee AJ and Davidson CL. Influence of light intensity on polymerization shrinkage and integrity of restoration-cavity interface. European Journal of Oral Sciences, 1995; 103; 322-6.

81. Watts DC and Hindi AA. Intrinsic 'soft-start' polymerization shrinkage-kinetics in an acrylate-based resin-composite. Dent Mater1999; 15: 39-45.

82. Silikas N, Eliades G, Watts DC. Light intensity effects on resin-composite degree of conversion and shrinkage strain. Dent Mater 2000; 16; 292-6.

83. Rueggeberg FA, Caughman WF and Curtis JW. Effect of light intensity and exposure duration on cure of resin composite. Operative Dentistry 1994; 19: 26-32.

84. Ernst CP, Kürschner R, Rippin G and Willershausen B. Stress reduction in resin-based composites cured with a two-step light-curing unit. Am J Dent 2000; 13: 69-72. 
85. Lim BS, Ferracane JL, Sakaguchi RL and Condon JR. Reduction of polymerization contraction stress for dental composites by two-step light-activation. Dental Materials 2002; 18: 436-44.

86. Mehl A, Hickel R and Kunzelmann KH. Physical properties and gap formation of light-cured composites with and without 'softstart-polymerization'. J Dent 1997; 25: 321-30.

87. Friedl KH, Schmalz G, Hiller KA and Märkl A. Marginal adaptation of Class V restorations with and without "Softstart-polymerization". Oper Dent 2000; 25: 26-32.

88. Sahafi A, Peutzfeldt A and Asmussen E. Soft-start polymerization and marginal gap formation in vitro. Am J Dent 2001; 14: 145-7.

89. Hofmann N, Siebrecht C, Hugo B and Klaiber B. Influence of curing methods and materials on the marginal seal of Class V composite restorations in vitro. Oper Dent 2003; 28: 160-7.

90. Peutzfeldt A, Sahafi A and Asmussen E. Characterization of resin composites polymerized with plasma arc curing units. Dent Mater 2000; 16: 330-6.

91. Irie M, Hatanaka K, Suzuki K, Watts DC. Immediate versus water-storage performance of Class V flowable composite restoratives. Dent Mater 2006; 22: 875-83.

92. Munksgaard EC, Irie M, Asmussen E. Dentin-polymer bond promoted by Gluma and various resins. J Dent Res 1985; 64: 1409-11.

93. Retief DH, Mandras RS, Russell CM. Shear bond strength required to prevent microleakage at the dentin/restoration interface. Am J Dent 1994; 7: 43-6. 
94. Peumans M, Kanumilli P, De Munck J, Van Landuyt K, Lambrechts P, Van Meerbeek B. Clinical effectiveness of contemporary adhesives: A systematic review of current clinical trials. Dent Mater 2005; 21: 864-81.

95. Van Landuyt KL, Peumans M, De Munck J, Cardoso MV, Ermis B, Van Meerbeek B. Three-year clinical performance of a HEMA-free one-step self-etch adhesive in non-carious cervical lesions. Eur J Oral Sci 2011; 119: 511-6.

96. Yokota H, Kawaguchi M, Yokota H, Kubo S, Hayashi Y. Effect of saliva contamination on dentin bond strengths of a self-etching primer system. Jpn J Conserv Dent 2003; 46: 916-24.

97. Munechika T, Suzuki K, Nishiyama M, Ohashi M, Horie K. A comparison of the tensile bond strengths of composite resins to longitudinal and transverse sections of enamel prisms in human teeth. J Dent Res 1984; 63: 1079-82.

98. Triolo PT, Swift EJ, Mudgil A, Levine A. Effect of etching time on enamel bond strengths. Am J Dent 1993; 6: 302-4.

99. Ferrari M, Mannocci F, Vichi A, Davidson CL. Effect of two etching times on the sealing ability of Clearfil Liner Bond 2 in Class V restorations. Am J Dent 1997; 10: 66-70.

100. Buonocore MG, Matsui A, Gwinnett AJ. Penetration of resin dental materials into enamel surfaces with reference to bonding. Arch Oral Biol 1968; 13: 61-70.

101. Van Landuyt KL, Kanumilli P, De Munck J, Peumans M, Lambrechts P, Van Meerbeek B. 
Bond strength of a mild self-etch adhesive with and without prior acid-etching. J Dent 2006; 34 :

$77-85$.

102. Duke ES. Clinical studies of adhesive systems: Oper Dent 1992; Supplement 5: 103-10.

103. Perdigão J, Dutra-Corrêa M, Castilhos N, Carmo ARP, Anauate-Netto C, Cordeiro HJD, Amore R, Lewgoy HR. One-year clinical performance of self-etch adhesives in posterior restorations. Am J Dent 2007; 20: 125-33.

104. Akimoto N, Takamizu M, Momoi Y. 10-year clinical evaluation of a self-etching adhesive system. Oper Dent 2007; 32: 3-10.

105. Hickel R, Roulet JF, Bayne S, Heintze SD, Mjör IA, Peters M, Rousson V, Randall R, Schmalz G, Tyas M, Vanherle G. Recommendations for conducting controlled clinical studies of dental restorative materials (Science committee project 2/98- FDI world dental federation). J Adhes Dent 2007; 9: 121-47.

106. Bayne S. Correlation of clinical performance with 'in vitro test' of restorative dental materials that use polymer-based matrices. Dent Mater 2012; 28: 52-71.

107. Chadwick B, Treasure E, Dummer P, Dunstan F, Gilmour A, Jones R, Phillips C, Stevens J, Rees J, Richmond S. Challenges with studies investigating longevity of dental restorations-a critique of a systematic review. J Dent 2001; 29: 155-61.

108. Hickel R, Peschke A, Tyas M, Mjör I, Bayne S, Peters M, Hiller KA, Randall R, Vanherle 
G, Heintze SD. FDI world dental federation - Clinical criteria for the evaluation of direct and indirect restorations Update and clinical examples. J Adhes Dent 2010; 12: 259-72.

109. Kubo S, Hayashi Y. Decision-making of treatment for restorations with marginal discoloration. J Jpn Conserv Dent 2011; the $134^{\text {th }}$ JSCD Meeting, Program and abstracts: Abstr. B-19.

110. Kubo S, Yamabe Y, Hayashi Y. Questionnaire study on decision-making in restorative treatment. J JDEA 2011; the 30 ${ }^{\text {th }}$ JDEA Meeting, Program and abstracts: 176, Abstr. P-135. 
Table 1 The effect of cavity designs on microleakage

\begin{tabular}{|c|c|c|c|c|c|c|}
\hline \multirow{2}{*}{$\begin{array}{l}\text { Cavity } \\
\text { designs }\end{array}$} & \multirow{2}{*}{\multicolumn{2}{|c|}{ Experimental groups }} & \multicolumn{4}{|c|}{ Dentin margins } \\
\hline & & & 0 & 1 & 2 & 3 \\
\hline \multirow[t]{4}{*}{$\mathrm{W}$} & LVR (-) & $15 \mathrm{~min}$ & 10 & & & \\
\hline & & $15 \min +\mathrm{TC}$ & 8 & 2 & & \\
\hline & & $24 \mathrm{~h}$ & 10 & & & \\
\hline & & $24 \mathrm{~h}+\mathrm{TC}$ & 10 & & & \\
\hline \multirow[t]{6}{*}{$\mathrm{V}$} & $\operatorname{LVR}(-)$ & $15 \mathrm{~min}$ & 4 & 4 & 2 & \\
\hline & & $15 \min +\mathrm{TC}$ & 4 & 3 & 3 & \\
\hline & & $24 \mathrm{~h}$ & 8 & 2 & & \\
\hline & & $24 \mathrm{~h}+\mathrm{TC}$ & 8 & 2 & & \\
\hline & $\operatorname{LVR}(+)$ & $15 \mathrm{~min}$ & 10 & & & \\
\hline & & $15 \min +\mathrm{TC}$ & 7 & 3 & & \\
\hline \multirow[t]{8}{*}{$\mathrm{U}$} & LVR (-) & $15 \mathrm{~min}$ & & 6 & 1 & 3 \\
\hline & & $15 \min +\mathrm{TC}$ & & 1 & 2 & 7 \\
\hline & & $24 \mathrm{~h}$ & 3 & 3 & 1 & 3 \\
\hline & & $24 \mathrm{~h}+\mathrm{TC}$ & & 1 & 3 & 6 \\
\hline & $\operatorname{LVR}(+)$ & $15 \mathrm{~min}$ & 9 & 1 & & \\
\hline & & $15 \min +\mathrm{TC}$ & 1 & 7 & 2 & \\
\hline & & $24 \mathrm{~h}$ & 9 & 1 & & \\
\hline & & $24 \mathrm{~h}+\mathrm{TC}$ & 8 & 2 & & \\
\hline
\end{tabular}

All cavities were restored with Liner Bond System (4-step etch and rinse, Kuraray Medical), whose enamel bond strength was significantly higher than dentin bond strength.

Microleakage did not occur at the incisal enamel margins.

LVR (+): Protect Liner, a low-viscosity resin composite, was applied according to the manufacturer's instructions.

LVR (-): cavities were restored without application of Protect Liner.

TC: specimens were subjected to thermocycle after assigned storage time. 
Table 2 The effect of cavity designs on microleakage of resin composites restored with Clearfil Liner Bond II

\begin{tabular}{|c|c|c|c|c|c|c|c|c|c|c|}
\hline \multirow{2}{*}{$\begin{array}{l}\text { Cavity } \\
\text { designs }\end{array}$} & \multirow{2}{*}{\multicolumn{2}{|c|}{$\begin{array}{l}\text { Experimental } \\
\text { groups }\end{array}$}} & \multicolumn{4}{|c|}{ Incisal margins } & \multicolumn{4}{|c|}{ Apical margins } \\
\hline & & & \multirow{2}{*}{$\frac{0}{10}$} & \multirow[t]{2}{*}{1} & \multirow[t]{2}{*}{2} & \multirow[t]{2}{*}{3} & \multirow{2}{*}{$\frac{0}{10}$} & \multirow[t]{2}{*}{1} & \multirow[t]{2}{*}{2} & \multirow[t]{2}{*}{3} \\
\hline $\mathrm{W}$ & ED & $24 \mathrm{~h}$ & & & & & & & & \\
\hline & & $\mathrm{TC}$ & & & 4 & 6 & 9 & 1 & & \\
\hline & DD & $24 \mathrm{~h}$ & 9 & 1 & & & 10 & & & \\
\hline & & $\mathrm{TC}$ & 4 & 5 & 1 & & 10 & & & \\
\hline \multirow[t]{4}{*}{$\mathrm{U}$} & ED & $24 \mathrm{~h}$ & 9 & 1 & & & 9 & 1 & & \\
\hline & & $\mathrm{TC}$ & 3 & 5 & 2 & & & 3 & 7 & \\
\hline & DD & $24 \mathrm{~h}$ & 10 & & & & 8 & 2 & & \\
\hline & & $\mathrm{TC}$ & 3 & 2 & 5 & & 1 & 2 & 7 & \\
\hline
\end{tabular}

All cavities were restored with Clearfil Liner Bond II (2-step self-etch, Kuraray Medical), whose dentin bond strength is comparable to enamel bond strength.

W: wedge-shaped cavity, U: U-shaped cavity

ED: cavities were prepared on labial surfaces at cementoenamel junction.

DD: cavities were prepared on labial root surfaces

TC: specimens were subjected to thermocycle after 15 minutes after light irradiation. 
Table 3 The effect of cavity designs on microleakge

\begin{tabular}{|c|c|c|c|c|c|c|c|c|c|c|}
\hline \multirow{2}{*}{ Adhesives } & \multirow{2}{*}{$\begin{array}{l}\text { Cavity } \\
\text { designs }\end{array}$} & \multirow{2}{*}{ Stresses } & \multicolumn{4}{|c|}{ Enamel margins } & \multicolumn{4}{|c|}{ Dentin margins } \\
\hline & & & 0 & 1 & 2 & 3 & 0 & 1 & 2 & 3 \\
\hline \multirow{4}{*}{$\begin{array}{l}\text { Photo Bond } \\
\text { (Kuraray Medical) }\end{array}$} & $\mathrm{W}$ & Cont. & 10 & & & & 7 & 3 & & \\
\hline & & $\mathrm{LC}$ & 10 & & & & 2 & 6 & 2 & \\
\hline & $\mathrm{U}$ & Cont. & 10 & & & & & 8 & 2 & \\
\hline & & $\mathrm{LC}$ & 10 & & & & & & 2 & 8 \\
\hline \multirow{4}{*}{$\begin{array}{l}\text { Liner Bond II V } \\
\text { (Kuraray Medical) }\end{array}$} & $\mathrm{W}$ & Cont. & 9 & 1 & & & 8 & 2 & & \\
\hline & & $\mathrm{LC}$ & 5 & & 5 & & 8 & 2 & & \\
\hline & $\mathrm{U}$ & Cont. & 6 & 1 & 3 & & 8 & 2 & & \\
\hline & & $\mathrm{LC}$ & 3 & 2 & 5 & & 3 & 1 & 4 & 2 \\
\hline \multirow{4}{*}{$\begin{array}{l}\text { Mac-Bond II } \\
\text { (Tokuyama Dental) }\end{array}$} & $\mathrm{W}$ & Cont. & 9 & 1 & & & 10 & & & \\
\hline & & $\mathrm{LC}$ & 4 & & 3 & 3 & 10 & & & \\
\hline & $\mathrm{U}$ & Cont. & 7 & 3 & & & 3 & 4 & 3 & \\
\hline & & $\mathrm{LC}$ & 7 & 2 & 1 & & 1 & 1 & 4 & 4 \\
\hline \multirow{4}{*}{$\begin{array}{l}\text { Single Bond } \\
\text { (3M ESPE) }\end{array}$} & $\mathrm{W}$ & Cont. & 9 & 1 & & & 8 & 2 & & \\
\hline & & $\mathrm{LC}$ & 10 & & & & 8 & 2 & & \\
\hline & $\mathrm{U}$ & Cont. & 9 & 1 & & & 2 & 7 & 1 & \\
\hline & & $\mathrm{LC}$ & 10 & & & & 1 & & 7 & 2 \\
\hline
\end{tabular}

W: wedge-shaped cavity, U: U-shaped cavity

Cont.: specimens were immersed in the dye solution immediately after 24-hour storage in water.

LC: specimens were subjected to flexural load cycling after 24-hour storage in water. 
Table 4 The effect of placement techniques on microleakage (U-shaped cavities)

\begin{tabular}{|c|c|c|c|c|c|c|}
\hline \multirow{3}{*}{$\begin{array}{r}\begin{array}{r}\text { Placement } \\
\text { techniques }\end{array} \\
\text { Bulk }\end{array}$} & \multirow{2}{*}{\multicolumn{2}{|c|}{$\begin{array}{l}\text { Experimental } \\
\text { groups }\end{array}$}} & \multicolumn{4}{|c|}{ Dentin margins } \\
\hline & & & \multirow{2}{*}{$\frac{0}{3}$} & \multirow{2}{*}{$\frac{1}{3}$} & \multirow{2}{*}{$\frac{2}{1}$} & \multirow{2}{*}{3} \\
\hline & $\operatorname{LVR}(-)$ & $24 \mathrm{~h}$ & & & & \\
\hline & $\operatorname{LVR}(+)$ & $24 \mathrm{~h}$ & 9 & 1 & & \\
\hline & & $\mathrm{TC}$ & 1 & 7 & 2 & \\
\hline \multirow{3}{*}{$\begin{array}{l}\text { Oblique } \\
2 \text { increments } \\
\text { (incisal first) }\end{array}$} & $\operatorname{LVR}(-)$ & $24 \mathrm{~h}$ & 8 & 1 & 1 & \\
\hline & $\operatorname{LVR}(+)$ & $24 \mathrm{~h}$ & 9 & 1 & & \\
\hline & & $\mathrm{TC}$ & 4 & 5 & 1 & \\
\hline \multirow{3}{*}{$\begin{array}{l}\text { Oblique } \\
2 \text { increments } \\
\text { (gingival first) }\end{array}$} & $\operatorname{LVR}(-)$ & $24 \mathrm{~h}$ & 7 & 1 & 1 & 1 \\
\hline & $\operatorname{LVR}(+)$ & $24 \mathrm{~h}$ & 8 & 2 & & \\
\hline & & TC & 3 & 5 & 2 & \\
\hline \multirow{3}{*}{$\begin{array}{l}\text { Parallel } \\
2 \text { increments }\end{array}$} & $\operatorname{LVR}(-)$ & $24 \mathrm{~h}$ & 1 & 2 & 4 & 3 \\
\hline & $\operatorname{LVR}(+)$ & $24 \mathrm{~h}$ & 8 & 2 & & \\
\hline & & TC & 1 & 6 & 3 & \\
\hline
\end{tabular}

All cavities were restored with Liner Bond System (4-step etch and rinse).

LVR (-): cavities were restored without the application of Protect Liner.

LVR (+): Protect Liner was applied according to the manufacturer's instructions.

$24 \mathrm{~h}$ : specimens were immersed in the dye solution after 24-hour storage in water.

TC: specimens were subjected to thermocycle 15 minutes after light activation. 
Table 5 The effect of low-viscosity resin composite lining on the microleakage (W-shaped cavities)

\begin{tabular}{|c|c|c|c|c|c|c|c|c|c|c|}
\hline \multirow{2}{*}{$\begin{array}{l}\text { Adhesive } \\
\text { systems }\end{array}$} & \multicolumn{2}{|c|}{ Experimental groups } & \multicolumn{4}{|c|}{ Enamel margins } & \multicolumn{4}{|c|}{ Dentin margins } \\
\hline & & LVR & 0 & 1 & 2 & 3 & 0 & 1 & 2 & 3 \\
\hline \multirow{6}{*}{$\begin{array}{l}\text { AQ Bond } \\
\text { (Sun Medical) }\end{array}$} & $24 \mathrm{~h}$ & - & 4 & 5 & 1 & & 7 & 3 & & \\
\hline & & + & 9 & 1 & & & 7 & 3 & & \\
\hline & $\mathrm{TC}$ & - & & 2 & 8 & & 1 & 7 & 2 & \\
\hline & & + & 4 & 4 & 2 & & 6 & 4 & & \\
\hline & $\mathrm{LC}$ & - & 2 & & 7 & 1 & 6 & 4 & & \\
\hline & & + & 5 & 3 & 2 & & 6 & 4 & & \\
\hline \multirow{6}{*}{$\begin{array}{l}\text { SE Bond } \\
\text { (Kuraray Medical) }\end{array}$} & $24 \mathrm{~h}$ & - & 8 & 2 & & & 8 & 2 & & \\
\hline & & + & 8 & 2 & & & 8 & 2 & & \\
\hline & $\mathrm{TC}$ & - & 3 & 4 & 3 & & 8 & 2 & & \\
\hline & & + & 7 & 3 & & & 8 & 2 & & \\
\hline & $\mathrm{LC}$ & - & 5 & 2 & 3 & & 7 & 3 & & \\
\hline & & + & 8 & 2 & & & 8 & 2 & & \\
\hline \multirow{6}{*}{$\begin{array}{l}\text { ABF (Protect Bond) } \\
\text { (Kuraray Medical) }\end{array}$} & $24 \mathrm{~h}$ & - & 8 & 2 & & & 7 & 3 & & \\
\hline & & + & 9 & 1 & & & 8 & 2 & & \\
\hline & $\mathrm{TC}$ & - & 6 & 1 & 3 & & 6 & 3 & 1 & \\
\hline & & + & 9 & 1 & & & 5 & 2 & 3 & \\
\hline & $\mathrm{LC}$ & - & 5 & 3 & 2 & & 7 & 2 & 1 & \\
\hline & & + & 8 & 2 & & & 8 & 2 & & \\
\hline
\end{tabular}

$24 \mathrm{~h}$ : specimens were immersed in the dye solution after 24-hour storage in water

TC: The specimens were subjected to thermocycle after 24-hour storage in water.

LC: specimens were subjected to flexural load cycling prior to immersion in the dye solution.

LVR: lining of a low-viscosity resin composite (Protect Liner F, Kuraray Medical) 
Table 6 Effect of resin composite type on microleakage (W-shaped cavities)

\begin{tabular}{|c|c|c|c|c|c|c|c|c|c|c|}
\hline \multirow{2}{*}{$\begin{array}{l}\text { Adhesive } \\
\text { systems }\end{array}$} & \multirow{2}{*}{$\begin{array}{c}\text { Filling } \\
\text { materials }\end{array}$} & \multirow{2}{*}{$\begin{array}{l}\text { Experimental } \\
\text { groups }\end{array}$} & \multicolumn{4}{|c|}{ Enamel margins } & \multicolumn{4}{|c|}{ Dentin margins } \\
\hline & & & 0 & 1 & 2 & 3 & 0 & 1 & 2 & 3 \\
\hline \multirow[t]{9}{*}{ AQ Bond } & Aelite Flo & Cont. & 3 & 5 & 2 & & 5 & 1 & 4 & \\
\hline & & $\mathrm{TC}$ & 1 & & 1 & 8 & & 2 & 1 & 7 \\
\hline & & $\mathrm{LC}$ & 5 & & 3 & 2 & 6 & 2 & & \\
\hline & Metafil Flo & Cont. & 5 & 5 & & & 4 & 1 & 5 & \\
\hline & & $\mathrm{TC}$ & & & & 10 & & 2 & 5 & 3 \\
\hline & & $\mathrm{LC}$ & 7 & 2 & 1 & & 6 & 2 & 2 & \\
\hline & AP-X & Cont. & 4 & 5 & 1 & & 7 & 3 & & \\
\hline & & $\mathrm{TC}$ & & 2 & 8 & & 1 & 7 & 2 & \\
\hline & & $\mathrm{LC}$ & 2 & & 7 & 1 & 6 & 4 & & \\
\hline \multirow[t]{9}{*}{$\mathrm{ABF}$} & Aelite Flo & Cont. & 8 & 2 & & & 6 & 4 & & \\
\hline & & $\mathrm{TC}$ & 1 & & 7 & 2 & 6 & 2 & 2 & \\
\hline & & $\mathrm{LC}$ & 8 & 1 & 1 & & 7 & 3 & & \\
\hline & Metafil Flo & Cont. & 8 & 2 & & & 7 & 3 & & \\
\hline & & $\mathrm{TC}$ & & & 8 & 2 & 1 & 2 & 7 & \\
\hline & & $\mathrm{LC}$ & 8 & 2 & & & 7 & 3 & & \\
\hline & AP-X & Cont. & 8 & 2 & & & 7 & 3 & & \\
\hline & & $\mathrm{TC}$ & 6 & 1 & 3 & & 6 & 3 & 1 & \\
\hline & & $\mathrm{LC}$ & 5 & 3 & 2 & & 7 & 2 & 1 & \\
\hline
\end{tabular}

Aelite Flo (a flowable composite), Metafil Flo (a flowable composite), AP-X (a hybrid composite)

Cont.: The specimens were immersed in the dye solution after 24-hour storage in water. 
Table 7 The effect of an enamel bevel on microleakage at the incisal enamel (W-shaped cavities)

\begin{tabular}{|c|c|c|c|c|c|}
\hline \multirow{2}{*}{$\begin{array}{l}\text { Adhesive } \\
\text { systems }\end{array}$} & \multirow{2}{*}{$\begin{array}{c}\text { Experimental } \\
\text { Groups }\end{array}$} & \multirow{2}{*}{ Bevel } & \multicolumn{3}{|c|}{ Enamel margins } \\
\hline & & & 0 & 1 & 2 \\
\hline \multirow[t]{4}{*}{ Liner Bond II } & Cont. & - & 8 & 2 & \\
\hline & $\mathrm{TC} *$ & - & & & 6 \\
\hline & $\mathrm{TC} *$ & + & 8 & 1 & 1 \\
\hline & $\mathrm{TC} *$ & PA & 10 & & \\
\hline Scotchbond & Cont. & - & 7 & 3 & \\
\hline \multirow[t]{3}{*}{ Multi-Purpose } & $\mathrm{TC} *$ & - & 2 & 1 & 7 \\
\hline & $\mathrm{TC} *$ & + & 7 & 2 & 1 \\
\hline & $\mathrm{TC} *$ & PA & 10 & & \\
\hline \multirow[t]{4}{*}{ Mac-Bond II } & Cont. & - & 9 & 1 & \\
\hline & $\mathrm{TC} *$ & - & & 2 & 8 \\
\hline & $\mathrm{TC} *$ & + & 4 & 6 & \\
\hline & $\mathrm{TC} *$ & PA & 10 & & \\
\hline \multirow[t]{6}{*}{ AQ Bond } & Cont. & - & 4 & 5 & 1 \\
\hline & $\mathrm{TC}$ & - & & 2 & 8 \\
\hline & $\mathrm{LC}$ & - & 2 & & 7 \\
\hline & Cont. & + & 10 & & \\
\hline & $\mathrm{TC}$ & + & 9 & 1 & \\
\hline & $\mathrm{LC}$ & + & 10 & & \\
\hline \multirow[t]{6}{*}{$\mathrm{ABF}$} & Cont. & - & 8 & 2 & \\
\hline & $\mathrm{TC}$ & - & 6 & 1 & 3 \\
\hline & $\mathrm{LC}$ & - & 5 & 3 & 2 \\
\hline & Cont. & + & 10 & & \\
\hline & $\mathrm{TC}$ & + & 9 & 1 & \\
\hline & $\mathrm{LC}$ & + & 10 & & \\
\hline
\end{tabular}

Cont.: specimens were immersed in the dye solution after 24-hour storage in TC*: specimens were subjected to thermocycle 15 minutes after light activati TC: specimens were subjected to thermocycle 24 hours after light activation LC: specimens were subjected to flexural load cycling after24-hour storage $\mathrm{j}$ -: without bevel, +: with bevel 
Table 8 The effect of light-curing modes on microleakage (W-shaped cavities)

\begin{tabular}{|c|c|c|c|c|c|c|c|c|c|}
\hline \multirow{2}{*}{ Curing modes } & \multirow{2}{*}{$\begin{array}{l}\text { Experimental } \\
\text { groups }\end{array}$} & \multicolumn{4}{|c|}{ Enamel margins } & \multicolumn{4}{|c|}{ Dentin margins } \\
\hline & & 0 & 1 & 2 & 3 & 0 & 1 & 2 & 3 \\
\hline \multirow[t]{2}{*}{ Standard mode } & Cont. & 8 & 2 & & & 7 & 3 & & \\
\hline & $\mathrm{TC}$ & 6 & 1 & 3 & & 6 & 3 & 1 & \\
\hline \multirow[t]{2}{*}{ Two-step mode } & Cont. & 6 & 4 & & & 5 & 2 & 3 & \\
\hline & $\mathrm{TC}$ & 4 & 6 & & & 4 & 2 & 4 & \\
\hline \multirow[t]{2}{*}{ Ramping mode } & Cont. & 8 & 2 & & & 5 & 2 & 3 & \\
\hline & $\mathrm{TC}$ & 6 & 4 & & & 2 & 4 & 4 & \\
\hline \multirow[t]{2}{*}{ PAC mode } & Cont. & 8 & 2 & & & 7 & 3 & & \\
\hline & $\mathrm{TC}$ & 4 & 6 & & & 4 & 2 & 4 & \\
\hline
\end{tabular}

All cavities were restored with ABF (Clearfil Protect Bond) in conjunction with Clearfil AP-X (a hybrid composite).

PAC: plasma arc curing

Cont.: specimens were immersed in the dye solution after 24-hour storage in water.

TC: specimens were subjected to thermocycle after 24-hour storage in water. 
Table 9 Tensile Bond strengths of adhesive systems used in our studies

\begin{tabular}{|c|c|c|c|}
\hline Adhesives & Manufacturer & Type & Enamel \\
\hline Photo Bond & Kuraray Medical & $\begin{array}{l}\text { conventional } \\
\text { total etch }\end{array}$ & 16.6 \\
\hline Liner Bond System & Kuraray Medical & 4-step ER & \\
\hline without Protect Liner & & & $19.1 *$ \\
\hline Imperva Bond (DP) & Shofu & 3 -step ER** & 6.5 \\
\hline Imperva Bond (Mix) & & & 26.0 \\
\hline Liner Bond II & Kuraray Medical & 2-step SE & 17.7 \\
\hline with Protectliner F & & & 19.4 \\
\hline with phosphoric acid & & & 19.8 \\
\hline $\begin{array}{l}\text { Scotchbond Multi-Purpose } \\
\text { with maleic acid }\end{array}$ & 3M Espe & 3-step ER & 15.7 \\
\hline $\begin{array}{l}\text { Scotchbond Multi-Purpose } \\
\text { with phosphoric acid }\end{array}$ & 3M Espe & 3-step ER & 17.3 \\
\hline All Bond 2 & Bisco & 3-step ER & 18.1 \\
\hline Mac-Bond II & Tokuyama dental & 2-step SE & 18.3 \\
\hline Single Bond & 3M Espe & 2-step ER & 18.9 \\
\hline Liner Bond II 2V & Kuraray Medical & 2-step SE & 17.4 \\
\hline SE Bond & Kuraray Medical & 2-step SE & 20.0 \\
\hline ABF [Protect Bond] & Kuraray Medical & 2-step SE & 20.6 \\
\hline One-Up Bond F & Tokuyama dental & 1-step SE & 18.0 \\
\hline AQ Bond & Sun Medical & 1-step SE & 9.6 \\
\hline iBond & Heraeus Kulzer & 1B 1-step SE & 10.9 \\
\hline G-Bond & $\mathrm{GC}$ & 1B 1-step SE & 15.5 \\
\hline One-Up Bond F Plus & Tokuyama dental & 1B 1-step SE & 16.8 \\
\hline $\mathrm{S}^{3}$ Bond & Kuraray Medical & 1B 1-step SE & 17.0 \\
\hline AQ Bond Plus & Sun Medical & 1B 1-step SE & 11.2 \\
\hline Absolute & Dentsply/Sankin & 1B 1-step SE & 13.6 \\
\hline
\end{tabular}

*: data was quoted from Hosoda et al [50].

**: manufacturer instructs that dentin is treated with Dentin Primer only DP: enamel and dentin were treated with Dentin Primer.

Mix: enamel and dentin were treated with a mixture of Etching Gel and Di PF: Protectliner F, a low viscosity resin, was applied prior to filling of the ER: etch-and-rinse system 
Table 10 Microleakge scores of 2-step self-etch and 3-step etch-and-rinse adhesives

\begin{tabular}{|c|c|c|c|c|c|c|c|c|c|c|}
\hline \multirow{2}{*}{ Adhesives } & \multirow{2}{*}{ Cavities } & \multirow{2}{*}{ Group } & \multicolumn{4}{|c|}{ Enamel margins } & \multicolumn{4}{|c|}{ dentin margins } \\
\hline & & & 0 & 1 & 2 & 3 & 0 & 1 & 2 & 3 \\
\hline \multirow[t]{4}{*}{ Liner Bond II } & $\mathrm{W}$ & Cont. & 8 & 2 & & & 10 & & & \\
\hline & & $\mathrm{TC}$ & & & 6 & 4 & 9 & 1 & & \\
\hline & $\mathrm{U}$ & Cont. & 9 & 1 & & & 9 & 1 & & \\
\hline & & $\mathrm{TC}$ & 2 & 4 & 4 & & 2 & 1 & 5 & 2 \\
\hline \multirow[t]{4}{*}{ Multi-Purpose } & $\mathrm{W}$ & Cont. & 7 & 3 & & & 8 & 2 & & \\
\hline & & $\mathrm{TC}$ & 2 & 1 & 7 & & 6 & 3 & 1 & \\
\hline & $\mathrm{U}$ & Cont. & 6 & 2 & 2 & & 6 & 4 & & \\
\hline & & $\mathrm{TC}$ & 2 & 3 & 5 & & 2 & 4 & 4 & \\
\hline \multirow{4}{*}{ All-Bond 2} & W & Cont. & 10 & & & & 8 & 2 & & \\
\hline & & $\mathrm{TC}$ & 9 & 1 & & & 6 & 2 & 2 & \\
\hline & $\mathrm{U}$ & Cont. & 10 & & & & 3 & 4 & 3 & \\
\hline & & $\mathrm{TC}$ & 9 & 1 & & & & 1 & 9 & \\
\hline
\end{tabular}

W: wedge-shaped cavity, U: U-shaped cavity

Cont.: specimens were immersed in the dye solution immediately after 24-hour storage in water.

TC: specimens were subjected to thermocycle after 15-minutes storage in water. 
Table 11 Microleakage scores of 1 bottle 1-setp self-etch adhesives (W-shaped cavities)

\begin{tabular}{|c|c|c|c|c|c|c|c|c|}
\hline \multirow{2}{*}{ Adhesives } & \multicolumn{4}{|c|}{ Enamel margins } & \multicolumn{4}{|c|}{ Dentin margins } \\
\hline & 0 & 1 & 2 & 3 & 0 & 1 & 2 & 3 \\
\hline iBond & 1 & & 7 & & 7 & 1 & & \\
\hline G-Bond & 1 & 2 & 5 & & 4 & 4 & & \\
\hline One-Up Bond F Plus & 4 & 2 & 2 & & 2 & 1 & 4 & 1 \\
\hline $\mathrm{S}^{3}$ Bond & 3 & 4 & 1 & & 6 & 2 & & \\
\hline AQ Bond Plus & & 1 & 7 & & 5 & 3 & & \\
\hline Absolute & & 1 & 7 & & 3 & 5 & & \\
\hline One-Up Bond $\mathrm{F} *$ & & & & 10 & 6 & 4 & & \\
\hline AQ Bond & & 2 & 8 & & 1 & 7 & 2 & \\
\hline Mac-Bond II & 5 & & 5 & & 8 & 2 & & \\
\hline SE Bond & 3 & 4 & 3 & & 8 & 2 & & \\
\hline
\end{tabular}

*: specimens were subjected to the thermocycle 15 minutes after light irradiation, except for OneUp Bond F.

One-Up Bond F and AQ Bond are earlier 1-step self-etch adhesives

Mac-Bond II and SE Bond are 2-step self-etch adhesives. 
Table 12 The effect of beforehand enamel etching on microleakage (W-shaped cavities)

\begin{tabular}{|c|c|c|c|c|c|c|c|c|c|}
\hline \multirow{2}{*}{$\begin{array}{l}\text { Adhesive } \\
\text { systems }\end{array}$} & \multirow{2}{*}{$\begin{array}{l}\text { Experimental } \\
\text { groups }\end{array}$} & \multicolumn{4}{|c|}{ Enamel margin } & \multicolumn{4}{|c|}{ Dentin margin } \\
\hline & & 0 & 1 & 2 & 3 & 0 & 1 & 2 & 3 \\
\hline \multirow{3}{*}{ Liner Bond II } & Cont. & & & 6 & 4 & 9 & 1 & & \\
\hline & PA & 7 & 1 & 2 & & 9 & & 1 & \\
\hline & $\mathrm{PA}(-)$ & 7 & 1 & 2 & & 8 & 1 & 1 & \\
\hline \multirow{3}{*}{$\begin{array}{l}\text { Schotchbond } \\
\text { Multi-Purpose }\end{array}$} & Cont. & 2 & 1 & 7 & & 6 & 3 & 1 & \\
\hline & PA & 7 & 1 & 2 & & 6 & 2 & 2 & \\
\hline & $\mathrm{PA}(-)$ & 6 & 1 & 3 & & 6 & 3 & 1 & \\
\hline Single Bond & & 9 & 1 & & & 6 & 4 & & \\
\hline Photo Bond & & 10 & & & & & & 5 & 5 \\
\hline
\end{tabular}

All specimens were subjected to thermocycle 15 minutes after light irradiation.

Cont.: cavities were treated with respective adhesive systems according to their instructions.

PA: enamel was etched with $37 \%$ acid for 15 seconds prior to the cavity treatment following the instructions.

PA (-): neither LB Primer nor maleic acid were applied to etched enamel walls.

For Single Bond and Photo Bond, enamel and dentin walls are simultaneously etched with phosphoric acid. 
Table 13 Questionnaire data for treatments of marginal discoloration (number of respondents*)

\begin{tabular}{lcccc}
\hline $\begin{array}{l}\text { Suggested } \\
\text { Treatments }\end{array}$ & $\begin{array}{c}\text { Case } \\
\mathrm{a}\end{array}$ & $\begin{array}{c}\text { Case } \\
\mathrm{b}\end{array}$ & $\begin{array}{c}\text { Case } \\
\mathrm{c}\end{array}$ & $\begin{array}{c}\text { Case } \\
\mathrm{d}\end{array}$ \\
\hline Monitoring & 78 & 75 & 30 & 16 \\
Refurbishing & 29 & 8 & 26 & 17 \\
Repair & 0 & 12 & 35 & 20 \\
Replacement & 2 & 14 & 18 & 56 \\
\hline
\end{tabular}

*: total number of respondents was 109. 


\section{Captions}

Fig. 1 Schematic drawing of the specimen set-up and flexural loading

The specimens were set on a testing machine so that the guide plane was located approximately $2.5 \mathrm{~mm}$ away from the vertical plane of the plunger. The table was repeatedly moved in a labio-lingual direction $3 \mathrm{~mm}$ against the stationary plunger. As a result, a lateral (labio-lingual or linguo-labial) displacement of approximately $0.5 \mathrm{~mm}$ was applied to the guide plane. Linguo-labial loading did not affect the marginal sealing [20].

Fig. 2 Lateral and labial views of cavity designs
L: inciso-apical width (mm)
D: cavity depth (mm)

A: cavosurface angle at the apical margin (degree)

C: C-factor

Fig. 3 Various placement techniques

Fig.4 Subdivision of criteria for the Bravo score on marginal discoloration 
(a) slight staining; (b) dark-colored localized (less than $1.5 \mathrm{~mm}$ in length) staining;

(c) dark-colored linear (more than $1.5 \mathrm{~mm}$ in length) staining

Fig. 5 Decision-making in treatments for various cases of marginal discoloration

Questionnaires including these pictures were sent to 250 randomly selected alumni of Nagasaki University School of Dentistry. Although 111 dentists responded to the questionnaire, 2 dentists did not answer all of the questions. As a result, the data obtained from 109 dentists was used for statistical analysis.

Fig. 6 Progress of marginal discoloration

(a) baseline (restored with Single Bond and Clearfil AP-X); (b) at 3-year recall (marginal discoloration occurred); (c) at 5-year recall; (d) at 14-year recall 
Fig. 1
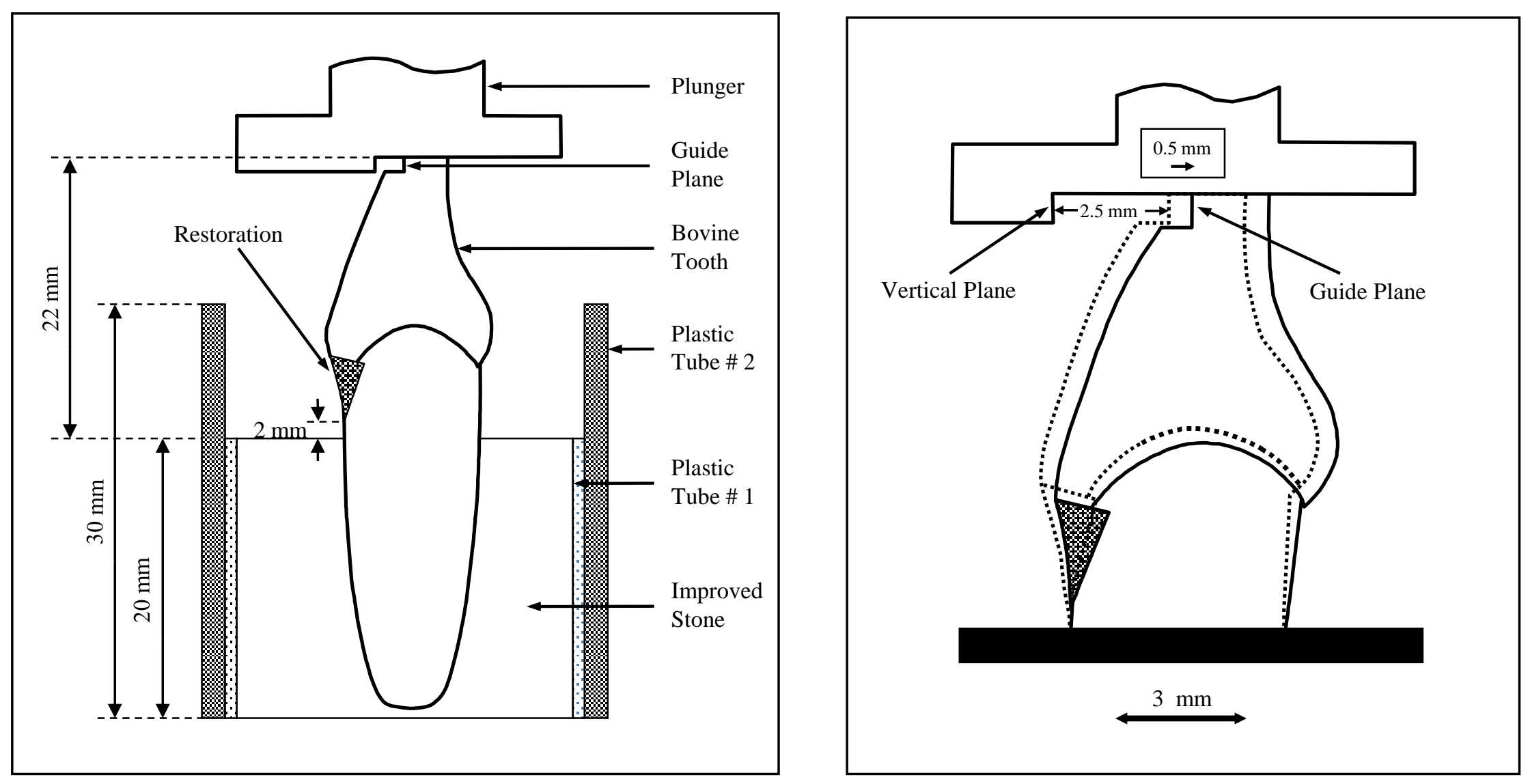
Fig. 2
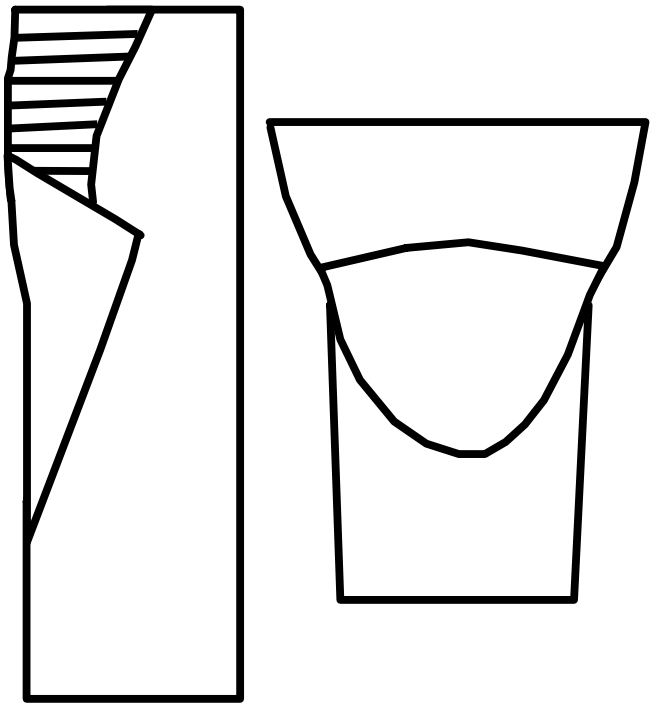

Wedge-shaped cavity

L: 3.0, D: 1.0, A: 165, C:1.3
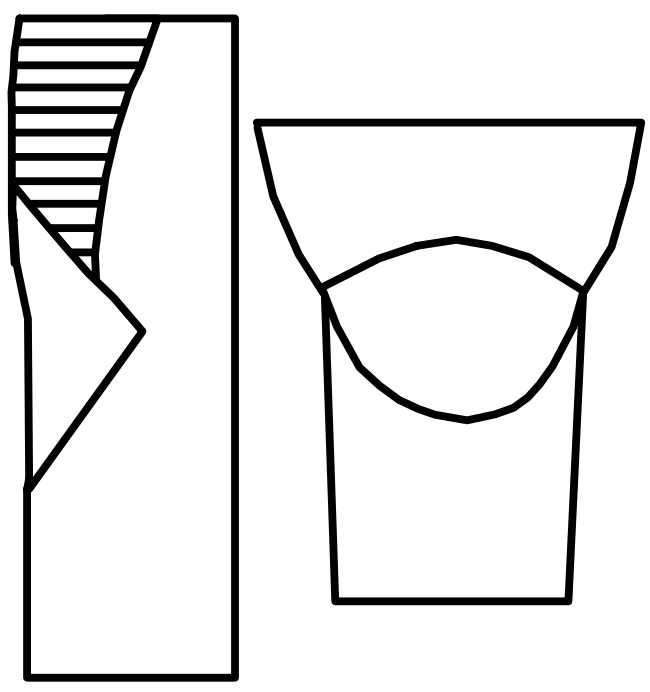

V-shaped cavity

L: 2.6, D: 1.0, A: 140, C:1.3

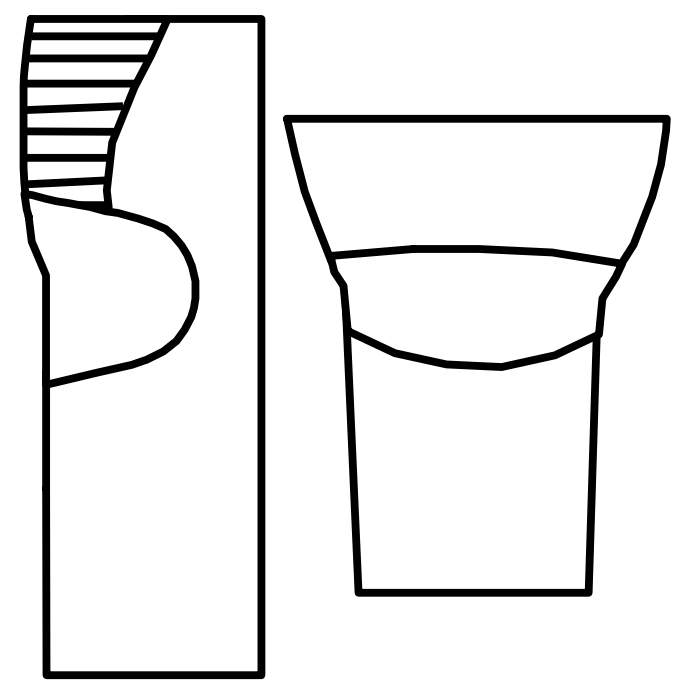

U-shaped cavity

L: 2.2, D: 1.5, A: 105, C:1.9 
Fig. 3

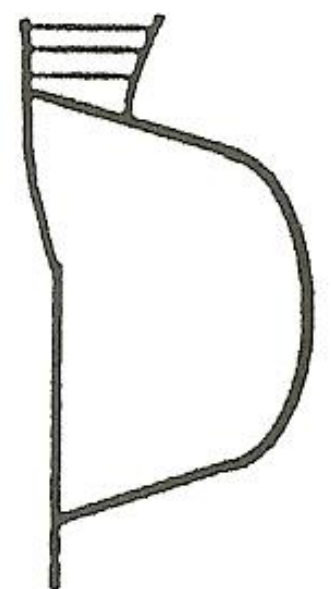

Bulk

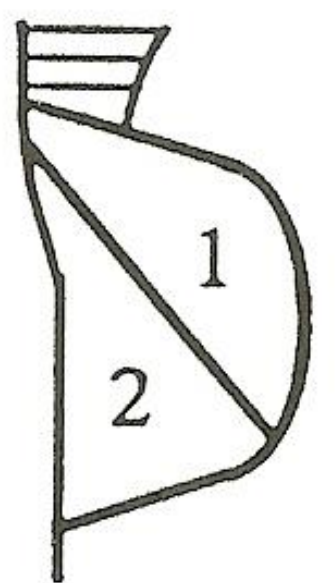

Oblique

2 increments (insical first)

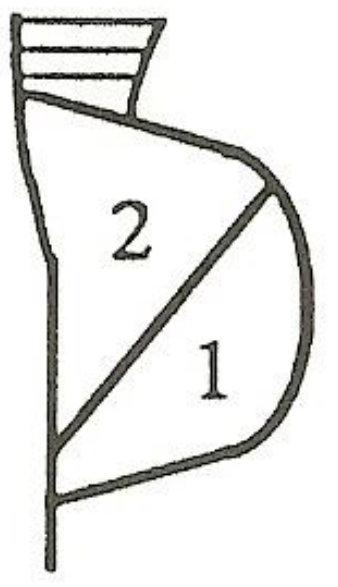

Oblique

2 increments

(gingival first)

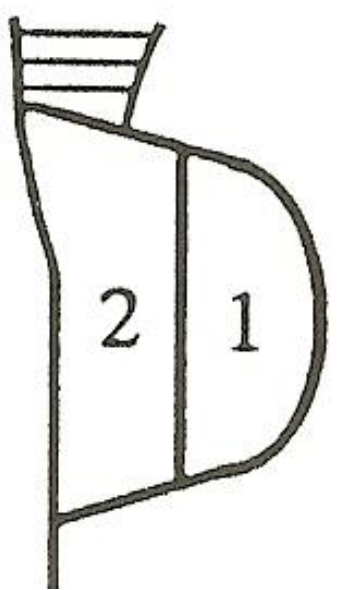

Parallel

2 increments 
Fig. 4
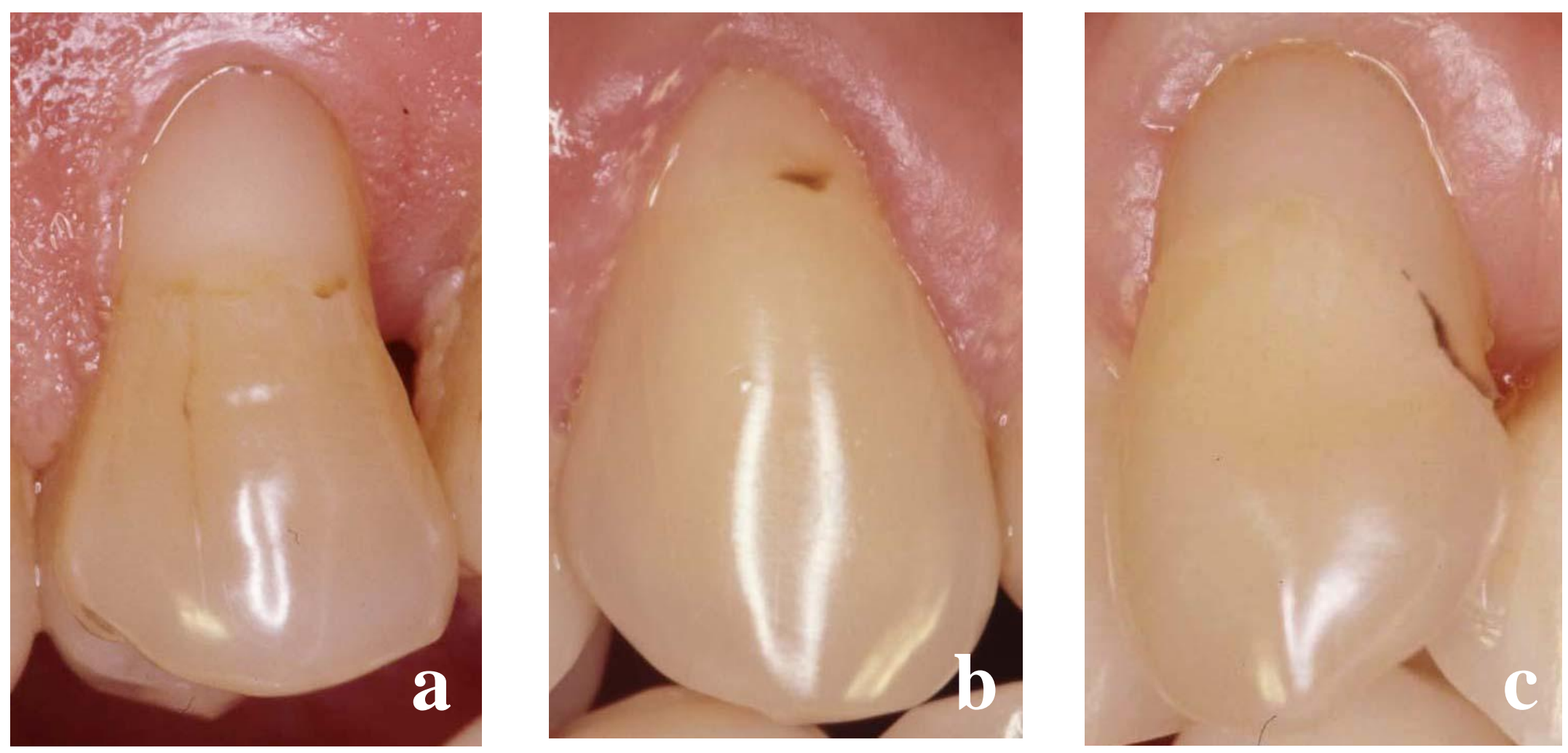
Fig. 5
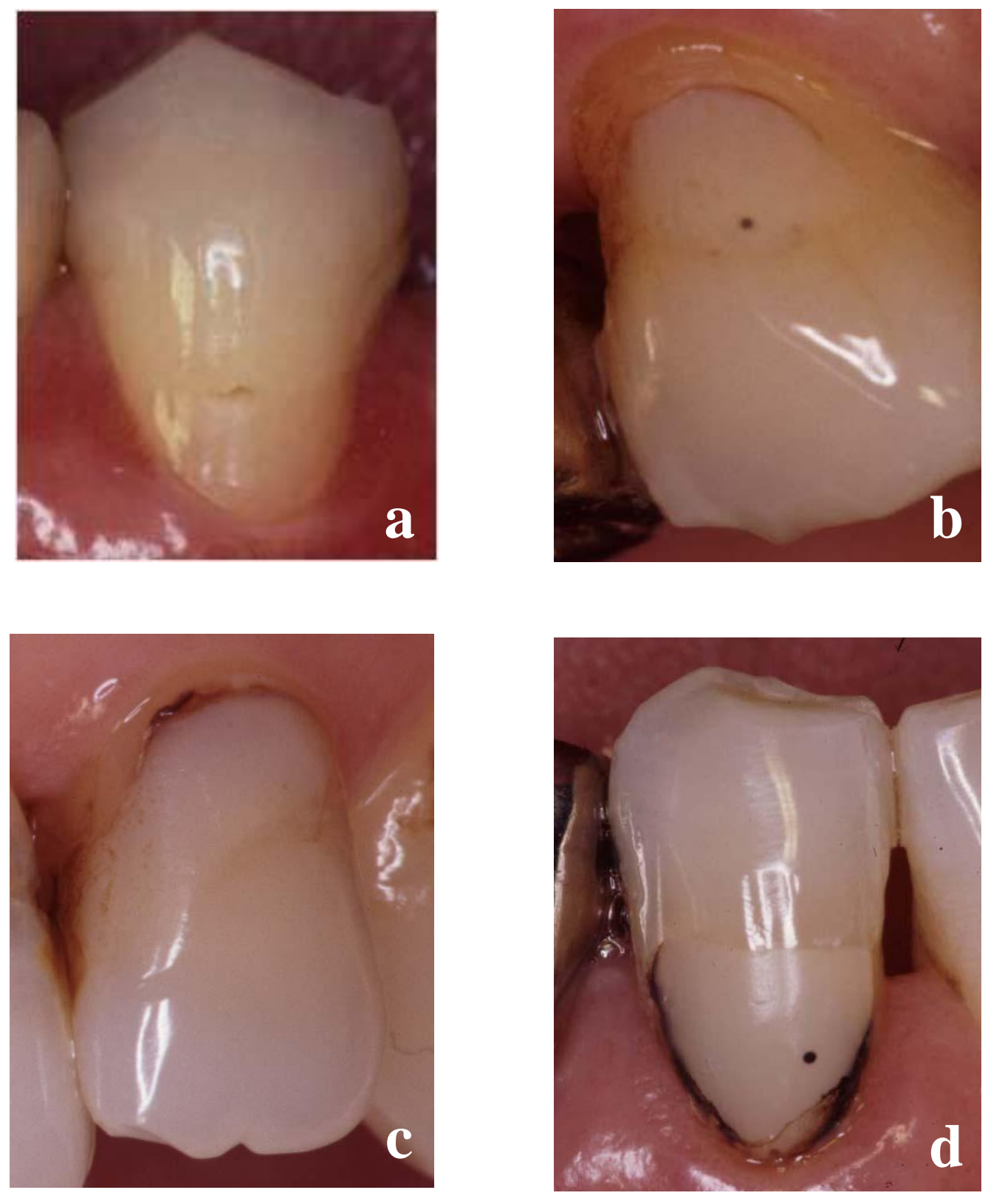
Fig. 6
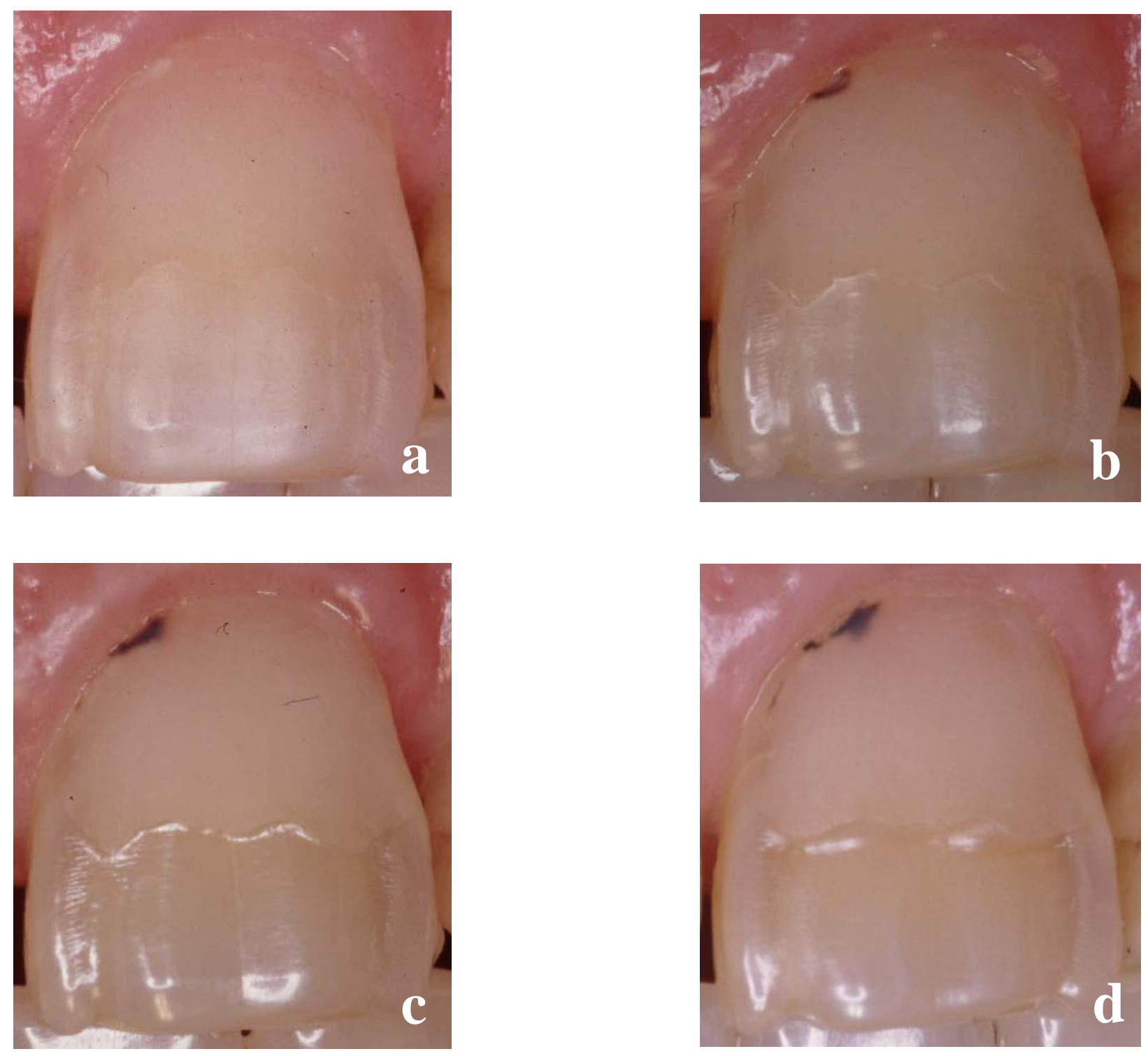